\title{
Tax Knowledge Diffusion via Strategic Alliances
}

\author{
Jens Müller \\ Paderborn University \\ jens.mueller@upb.de
}

Arndt Weinrich

Paderborn University

arndt.weinrich@upb.de*

Acknowledgements: We thank Alissa Brühne (discussant), Alex Edwards and Alastair Lawrence for their helpful comments. We also thank the participants at the 2019 annual meeting of the foundation Stiftung Prof. Dr. Westerfelhaus, the 2019 arqus Conference, the $5^{\text {th }}$ Berlin-Vallendar Conference on Tax Research and the $6^{\text {th }}$ Annual MaTax Conference. We further acknowledge the helpful discussions with our colleagues at the TAF Department at Paderborn University. Financial support by the foundation Stiftung Prof. Dr. oec. Westerfelhaus (Bielefeld, Germany) is gratefully acknowledged.

*Send correspondence to Arndt Weinrich, Paderborn University, Faculty of Business Administration and Economics, Warburger Str. 100, DE 33098 Paderborn. 


\title{
Tax Knowledge Diffusion via Strategic Alliances
}

\author{
November 2019 \\ Working Paper
}

\begin{abstract}
This study examines strategic alliances as channels for tax knowledge diffusion between firms. Despite solid insights on within-firm determinants of tax planning, little is known about tax knowledge diffusion via cross-firm connections. Since theory suggests that the role of strategic alliances in tax knowledge diffusion is ambiguous, we test our notion empirically. To tease out potential tax knowledge diffusion, we analyze changes in the tax planning behavior of high-tax firms in strategic alliances with low-tax firms in comparison to high-tax firms in strategic alliances with other high-tax firms. We apply a multivariate regression model, a difference-in-differences approach and use basic textual analysis to identify the main business purpose of a strategic alliance. We find a substantial increase in the tax planning behavior of high-tax firms in strategic alliances with low-tax firms relative to high-tax firms in high-tax strategic alliances. Additionally, our results suggests that high-tax firms are able to adjust their tax planning behavior within two years of network initiation when cooperating with low-tax firms. Because we are also able to provide a series of robustness checks, we interpret the identified responses to be consistent with existing tax knowledge diffusion via strategic alliances.
\end{abstract}

Keywords: Corporate Tax Planning/Avoidance, Knowledge Diffusion, Network, Strategic Alliance.

JEL Qualification: C31, G34, H26.

Data: Data are available from public and/or subscription-based sources identified in the paper.

Declarations of interest: None. 


\section{Introduction}

Varying levels of control and commitment to affiliates allow a firm to tailor its operational organization to its actual needs. One means of striving for optimal corporate institutionalization is cooperation with other firms. The relevance of this investment alternative is emphasized by the observation that firms currently plan to disrupt other industries by entering them via partnerships and cooperation (PwC, 2018). Generally, cooperation is expected to lead to information gathering and knowledge spillovers (e.g., see Higgins and Rodriguez (2006)), which are intuitively desirable for both investing firms and outsiders, such as governmental institutions. However, recent literature suggests that cross-firm connections could play a crucial role in the diffusion of tax planning practices between firms. Consequently, the perception and valuation of such spillovers would highly depend on the respective point of view. To the best of our knowledge, very little is known about the interplay of cooperation and corporate taxation. Thus, the key innovation of our study lies in analyzing whether strategic alliances serve as channels for tax knowledge diffusion between firms.

Generally, corporate cooperation is arranged either as a separate legal entity with equity participations for the involved parties or on a contractual basis. While the former type is usually referred to as (equity) joint venture, the latter is a so-called strategic alliance. Differences between joint ventures and strategic alliances are, however, not limited to their contractual/equity basis. Basically, strategic alliances may be regarded as "lying somewhere in between single-firm activity and spot contracting" (Lindsey, 2008), involving mutual commitment not typically found in arm's-length market transactions but having less impact on the partnering firms' operations than equity joint ventures (Chan et al., 1997). In contrast to equity joint ventures, strategic alliances themselves are not subject to corporate taxation. This is useful for us, as we are not interested in whether firms potentially use joint ventures as vehicles in tax planning activities but in whether cooperation may serve as a channel through which tax knowledge diffuses between firms. We thereby define tax knowledge as a firm's ability to maximize its nonconforming tax planning activities.

We empirically exploit information on strategic alliances, which we also refer to as "networks", between publicly traded US firms. Given that accounting data are available for a network's participants, we 
reshape data from the alliance to the participant level (network-firm-observations). Our base sample contains 4,159 network-firm-observations, which translate to 2,064 strategic alliances by 1,603 unique firms and 19,447 overall firm-year-observations between 1994 and 2016. Among these observations, we identify low-tax and high-tax networks. These are characterized by the presence of at least one lowtax firm as a participant or by initiation by undersheltered firm respectively (high-tax firms). To tease out (potential) tax knowledge diffusion, we analyze changes in the tax planning behavior of high-tax firms in strategic alliances with low-tax firms in comparison to high-tax firms in strategic alliances with high-tax firms. Thereby, we rule out alternative explanations, such as the overall influence of a network on a firm's tax planning behavior or reversion to the mean. We gain insights into the actual business of a network by applying a basic textual analysis approach. For our inferences, we apply a multivariate regression design and a difference-in-differences (DiD) model, which both complement a descriptive analysis. Covariates on partner, network and firm characteristics are included in the regression models and account for a broad range of influences. We find a substantial increase in the tax planning behavior, measured as cash taxes paid, of high-tax firms in strategic alliances with low-tax firms relative to hightax firms in high-tax strategic alliances. Consequently, the results from our analyses support strategic alliances as channels through which tax knowledge diffuses between firms. Additionally, we test whether partner characteristics intensify or mitigate the identified learning effects but find that tax knowledge diffusion via strategic alliances is rather unaffected by such heterogeneity.

Our study refers to the emerging literature on channels through which tax knowledge diffuses between firms. Despite solid insights on within-firm determinants of tax planning (Lisowsky, 2010), little is known about cross-firm connections in this field. By examining a potential determinant of crosssectional variation in tax planning practices among firms, we follow the calls for contributions to the understanding of this matter (Cen et al., 2018; Dyreng and Maydew, 2017; Wilson, 2009). Recent research has turned to cross-firm connections, analyzing board ties (Brown, 2011; Brown and Drake, 2014), banks (Gallemore, Gipper, and Maydew, 2018), human capital turnover (Barrios and Gallemore, 2018), auditors (Frey, 2018; Lim et al., 2018) and the supply chain (Cen et al., 2017, 2018). We extend this literature by analyzing the role of strategic alliances in tax knowledge diffusion. Since strategic alliances are established on a peer-to-peer basis between the participants and are thus directly associated 
with a firm's organizational level, we discuss whether networks provide a conceptual framework for successful tax knowledge diffusion. Subsequently, we test our notion empirically.

We further contribute to the management literature on knowledge diffusion via strategic alliances. Empirical inferences in such studies are usually based on the contracting parties' stock price performance (Boone and Ivanov, 2012; Mohanram and Nanda, 1996; Chen, King, and Wen, 2015; Anand and Khanna, 2000), return on equity, (cash flow) return on assets (Chan et al., 1997; Porrini, 2004) and post-reorganization performance (Cai and Sevilir, 2012; Higgins and Rodriguez, 2006; Ishii and Xuan, 2014; Porrini, 2004). While firms are often found to benefit from what they learn in alliances in other contexts, not all corporate practices diffuse in the same way (Cai et al., 2014). To the best of our knowledge, we are the first to measure knowledge diffusion via strategic alliances based on a firm's tax planning behavior. Our study therefore not only aligns with accounting and management research but also develops a new measure of knowledge diffusion via strategic alliances.

In the next section, we thoroughly review the related literature to discuss how tax knowledge diffuses between firms and which role strategic alliances could take in such diffusion. Subsequently, we explain our data exploitation and identification strategies. We discuss an appropriate research design and then present and discuss the results of our study. Before this paper closes with a brief conclusion, we provide several sensitivity analyses. 


\section{Conceptual Framework \& Prior Literature}

\subsection{Channels for Tax Knowledge Diffusion}

The extensive research that considers firm-level characteristics to explain the development and variation of tax planning activities by firms underlines the perceived importance of corporate taxes in economic theory, politics and society (for comprehensive reviews, see Hanlon and Heitzman (2010) and Wilde and Wilson (2018)). Despite these solid insights on the within-firm determinants of tax planning (Lisowsky, 2010), little is known about tax knowledge diffusion via cross-firm connections. Given the substantial economic impact of tax planning activities (Tørsløv, Wier, and Zucman, 2018), one intuitively aligns practices by tax advisors with increased tax planning. Recent research suggests the existence of further channels, by investigating tax planning ecosystems between firms. Consequently, a "better understanding of the actual tax strategies being used" is needed (Dyreng and Maydew, 2017). Brown (2011) pioneered in this literature strand by examining the spread of a specific tax planning tool, the corporate-owned life insurance shelter. While she finds that board interlocks and (to some extent) geographical proximity increase the probability that a firm adopts the shelter from a prior user, she does not find significant shelter adoption via shared audit firms. The latter result, although theoretically convincing due to independence regulations on audit services, is somewhat surprising given the large literature on auditors trespassing their limited scope of function (Aobdia, 2015; Cai et al., 2016; Dhaliwal et al., 2016; McGuire, Omer, and Wang, 2012). Calibrating from the audit-firm level to the individual audit engagement partner, Frey (2018) suggests that the engagement of a German tax certified auditor, who signals high competency in taxes, is associated with higher effective tax rates at client firms. In contrast, Lim et al. (2018), find that Chinese firms with stronger connections to low-tax firms through individual audit partners show lower effective tax rates. Further disentangling intermediaries as channels for tax knowledge diffusion, Barrios and Gallemore (2018) document that firms exhibit increasing tax planning when they hire tax staff from sophisticated tax planners. This finding is consistent with inferences from analyzing board ties to low-tax firms (Brown and Drake, 2014). Gallemore, Gipper, and Maydew (2018) show that firms experience meaningful tax reductions when they start a relationship with a bank whose existing clients engage in tax planning. 
[Figure 1]

These studies are conceptually aligned by the presence of intermediaries who implement tax planning expertise in their set of contracts and transfer the tax knowledge gained to other parties they are contracting with. Intermediaries are found to play a key role in the acquisition and dissemination of information in many research fields (e.g., see Di Maggio et al. (2019)). In the context of tax knowledge diffusion, this could, for instance, be perceived as a violation of auditor independence (McGuire, Omer, and Wang, 2012). Figure 1 categorizes prior research on channels through which tax knowledge diffuses. It aligns the framework (institutional setting) to identified channels. While research on tax knowledge diffusion focuses on the role of intermediaries, Cen et al. (2017) and Cen et al. (2018) analyze peer-to-peer contracting between firms. Specifically, they focus on tax knowledge diffusion via the supply chain and document that customers and suppliers both increase tax planning activities once their relationship is considered dependent. Strikingly, Cen et al. (2018) suggest that customers and their suppliers share tax planning benefits through lower product prices. While evidence for intended sharing of tax benefits is scarce (for instance, see Erickson (1998) and Erickson and Wang (1999)), an explicit transfer of tax knowledge aligns the "supply chain channel" with research on intermediaries. 


\subsection{Strategic Alliances and Tax Knowledge Diffusion}

With our study, we broaden the research on how tax knowledge diffuses between firms via peer-to-peer contracting. We therefore elaborate on different characteristics of tax knowledge, which could impede or facilitate spillovers in strategic alliances, and subsequently resolve whether strategic alliances establish an organizational form of collusion that allows for knowledge spillovers.

\subsubsection{Tax Knowledge}

Repeated business transactions are found to enable knowledge spillovers (Isaksson, Simeth, and Seifert, 2016). However, not all corporate practices diffuse in the same way (Cai et al., 2014), as major barriers to knowledge spillovers are shown to be knowledge-related factors (Szulanski, 1996). While explicit knowledge can easily be codified and is systematically transferable, tacit knowledge is hard to formulate and communicate because it "is deeply rooted in action, commitment, and involvement in a specific context" (Nonaka, 1994). Consequently, the more (tax) knowledge qualifies as explicit, the more easily transferable it should be (Meier, 2011). When classifying tax knowledge, one might reflexively refer to it as tacit given the substantial complexity of corporate taxes (Hoppe et al., 2019) and the increased uncertainty (Dyreng, Hanlon, and Maydew, 2018; Guenther, Matsunaga, and Williams, 2017) and costs of (Hundsdoerfer and Jacob, 2018) tax planning. One also has to consider that know-how is somewhat sticky, difficult to codify and therefore more tacit than pure information (Kale, Singh, and Perlmutter, 2000). However, anecdotal evidence suggests that tax shelters, such as the German family office shelter for limited partnerships, are repetitive among firms and not limited to a particular industry. Recent findings suggest tax knowledge to rather be of explicit nature, given the inferences on the corporateowned life insurance shelter (Brown, 2011) or lease-in, lease-out transactions (Wilson, 2009). Lisowsky (2010) further argues that a significant portion of tax shelters serve as mass market tax saving ideas for advisors.

\subsubsection{Successful (Tax) Knowledge Diffusion}

According to Rogers (2003), diffusion requires communication through channels over time among members of a social system. In accomplishing a common goal, the contracting parties of a strategic 
alliance are engaged in joint problem solving via a social system. Consistent with this, cooperation is found to mitigate problems ensuing from cultural differences (Kogut and Singh, 1988). Spillovers are also more likely to occur in cases of an high frequency of interactions between firms (Isaksson, Simeth, and Seifert, 2016) and with increasing partner trustworthiness (Jiang et al., 2016). Regarded as "lying somewhere in between single-firm activity and spot contracting" (Lindsey, 2008) and presenting increased mutual commitment in comparison to arm's-length market transactions (Chan et al., 1997), strategic alliances further comply with the diffusion requirements proposed by Rogers. Empirical inferences about knowledge diffusion via strategic alliances are usually based on the contracting parties' stock price performance (Boone and Ivanov, 2012; Mohanram and Nanda, 1996; Chen, King, and Wen, 2015; Anand and Khanna, 2000), return on equity, (cash flow) return on assets (Chan et al., 1997; Porrini, 2004) and post-reorganization performance (Cai and Sevilir, 2012; Higgins and Rodriguez, 2006; Ishii and Xuan, 2014; Porrini, 2004). Other scholars apply exploratory approaches by conducting surveys (Dyer and Hatch, 2006) or interviews (Inkpen, 2008). Often, firms are found to benefit from what they learn in alliances in other contexts (Porrini, 2004). Based on these findings, strategic alliances should provide a good channel for the successful diffusion of tax knowledge.

Although cooperation is found to be associated with knowledge spillovers, tension arises from various aspects. First, limits to the recipient's absorptive capacity create a barrier to knowledge diffusion (Dyer and Hatch, 2006; Szulanski, 1996). With regard to tax planning, cooperation could also induce complexity in the contracting parties' organization and reduce a firm's ability to fine-tune the tax sheltering of its affiliates (Desai, Foley, and Hines, 2004). Additionally, both cooperation (Chen, King, and Wen, 2015) and tax planning are found to increase an organization's uncertainty (Dyreng, Hanlon, and Maydew, 2018). Thus, even prudent managers could expect the marginal disutility of uncertainty to exceed the benefits of acquired tax knowledge. Furthermore, firms need to find ways not only to derive critical know-how from their alliance partners but also to protect themselves from losing their own core capabilities (Kale, Singh, and Perlmutter, 2000). Khanna, Gulati, and Nohria (1998) frame this in the context of earning private benefits in an alliance, which permits the firm to apply what it learns to its business outside the scope of the alliance and therefore harms the cooperation by inducing underinvestment in shared learning. 
Inkpen (2000) describes learning through networks as a multi-stage process, consisting of forming a network, gaining access to knowledge and adopting the knowledge. However, there is little evidence on how knowledge diffusion (i.e., spillover) occurs. Chan et al. (1997) identify optimal decision making authority, organizational flexibility and control of opportunistic behavior as major drivers for value creation within a strategic alliance. Khanna, Gulati, and Nohria (1998) argue that although contracting parties must invest in learning, both parties need not earn private benefits. They argue that a firm [with poor tax knowledge $]^{1}$ would not have an incentive to continue the alliance once it had earned private benefits [tax knowledge spillover] if its private benefits exceeded the common benefits. The other party [with sophisticated tax knowledge] would then "race" to earn benefits itself before termination of the alliance. As such racing behaviors appear to be mutually reinforcing, common benefits would still be attainable (Khanna, Gulati, and Nohria, 1998). Furthermore, strategic alliances enhance managerial flexibility because the contracting parties are not fully committed to the investment (Chen, King, and Wen, 2015), while Fiol and Lyles (1985) highlight that the probability of learning increases with an organizational structure that allows innovativeness and new insights. Employees who are seconded to a strategic alliance are involved in not only the alliance's business as such but also the monitoring of the alliance and the partner. Within-organization reporting thus creates opportunities for experiencesharing. The observation of tax planning effectively implemented by other participants in a network could increase a firm's management confidence in implementing the respective tax planning activity as well. This learning by observation would be consistent with knowledge diffusion being a gradual process of dissemination (Szulanski, 1996), with increasing probability of uniformity of actions over time in networks (Gale and Kariv, 2003) and with anecdotal evidence on tax advisors heavily pitching tax planning ideas across the population of firms with only partial success from the spot. Gained confidence could overcome the (irrational) fear of reputational costs from engaging in tax planning (Gallemore, Maydew, and Thornock, 2014; Hanlon and Slemrod, 2009). With regard to supply chains, Cen et al. (2018) suggest that intentional tax knowledge transfers enhance or at least maintain supply chain

\footnotetext{
${ }^{1}$ Content in square brackets is added by the authors.
} 
stability. Strategic alliances are also exposed to instability that is inherent in their institutionalization and specific to cooperation. Cultural differences, product market competition, availability of new technology, cost differences, market entry barriers, deadlocks, or imitation of a partner cause this instability. Participants in a strategic alliance could therefore follow the intuition of Cen et al. (2018) and share tax knowledge to establish bonding mechanisms.

Given the aforementioned variety of potential mechanisms, we do not expect that tax knowledge diffusion via strategic alliances is exposing itself in (one) specific accounting measure(s). Rather more, the experiences of others and the communication structure between parties (analytically) explain information flows (Acemoglu et al., 2011; Blonski, 1999). Consequently, we expect tax knowledge diffusion via strategic alliances to be driven by several soft factors. If we observed actual exploitation of opportunities for tax knowledge diffusion, we could shed light on knowledge spillovers in peer-topeer contracting. Thus, it remains an empirical question whether strategic alliances actually serve as channels for tax knowledge diffusion between firms. 


\section{Data}

\section{[Table 1]}

\subsection{Sample Construction}

We exploit data on strategic alliances from Securities Data Company's (SDC) Platinum database on strategic alliances over the period $1994-2016 .^{2}$ SDC is widely used in relevant research on corporate cooperation (Anand and Khanna, 2000; Boone and Ivanov, 2012; Cai and Sevilir, 2012; Chen, King, and Wen, 2015; Ishii and Xuan, 2014), and its accuracy is generally perceived as very high for most items (Anand and Khanna, 2000). SDC issues data at the strategic alliance level. We reshape data from the alliance to the participant level because accounting data are available for the (publicly traded) contracting parties. For instance, a strategic alliance between two participants translates to a networkfirm-observation for each of the two firms. Compustat provides us with firm-year-level accounting information, and we merge SDC and Compustat data using a firm's six-digit CUSIP number (at the level of the ultimate parent of the participant) as an identifier. Although SDC provides reliable networkobservations from the beginning of 1990 onwards, we start our sample in 1994 due to changes in reporting requirements on cash taxes paid (Cen et al., 2017). We end our sample in 2016 to exclude any inferences from the 2017 US tax reform. Furthermore, we respectively consider strategic alliances between publicly traded firms incorporated and headquartered in the US and in which all contracting parties are identified in Compustat (Table 1 Panel A). Our base sample contains 4,159 network-firmobservations, which translate to 2,064 strategic alliances by 1,603 unique firms and 19,447 overall firmyear-observations.

\footnotetext{
${ }^{2} \mathrm{~A}$ list of the requested data items is available from the authors upon request.
} 


\subsection{Identification Strategy}

[Figure 2]

\subsubsection{Measuring Tax Knowledge}

For purposes of this study, we define tax knowledge as a firm's ability to maximize its nonconforming tax planning activities. The lingua franca in measuring the degree to which a firm is able to succeed in this attempt is the effective tax rate, which puts tax expenses and pre-tax book income into perspective. The interpretation of effective tax rates is fairly straightforward, and an advantage is that, even though conceptually incorrect, they are widely used as input for corporate decisions on new investment (Graham et al., 2017). We base our inferences on the cash effective tax rate (cash ETR) because cash ETR also captures tax deferral strategies (Hanlon and Heitzman, 2010). Furthermore, we apply a multi-period (3year) form of cash ETR (Brown and Drake, 2014; Barrios and Gallemore, 2018; Gallemore, Gipper, and Maydew, 2018), because we expect tax knowledge spillovers to occur more likely over time.

$$
\operatorname{cash} \operatorname{ETR}_{i, t=1}=\frac{\sum_{t=1}^{3}\left(\operatorname{txpd}_{i, t}\right)}{\sum_{t=1}^{3}\left(p i_{i, t}-s p i_{i, t}\right)}
$$

The terms txpd, pi and spi correspond to their Compustat data item equivalents of cash taxes paid, pretax income and special items. Missing spi are reset to 0 , while any cash ETR3 with a negative denominator is reset to missing. Non-missing cash ETR3 are winsorized at 0 and 1 . By nature of this approach, cash ETR3 would always be missing for the final (penultimate) firm-year of a firm in our panel. For the final (penultimate) firm-year, we therefore substitute cash ETR3 with $\operatorname{cash} \operatorname{ETR}(2)$. Applying a forward-looking cash ETR3 comes with the advantage that potential tax knowledge spillovers from strategic alliances can be directly linked to the year of network initiation.

\subsubsection{Low-tax and High-tax Networks}

For tax knowledge spillovers to occur, at least one network participant must possess sophisticated tax knowledge. Therefore, we classify the strategic alliances in our dataset into low-tax and high-tax networks. Applying a forward-looking cash ETR3 for our output analysis has the advantage of aligning any influence on the cash ETR3 directly to the year of network initiation. However, identifying low- 
tax networks based on a forward-looking measurement would come with the disadvantage of concluding the type of input based on the output. For the identification of low-tax networks, we therefore consider a form of the cash ETR3, which is constructed over a three-year preceding period:

$$
\text { pre cash } \operatorname{ETR} 3_{i, t=0}=\frac{\sum_{t=-2}^{0}\left(\operatorname{txpd}_{i, t}\right)}{\sum_{t=-2}^{0}\left(p i_{i, t}-s p i_{i, t}\right)}
$$

For every $t=1$ in which a new network is initiated, we consider the participants' initial pre cash ETR3, which is constructed from $t=-2$ to $t=0$. For the first (second) firm-year of a firm in our panel, we substitute pre cash ETR3 with pre cash ETR(2). To increase the accuracy of our analysis, we require to observe the cash ETR 3 and pre cash ETR 3 of all participants in a network to be considered in our analysis (Table 1 Panel B). Figure 2 provides additional information regarding how we classify firms and networks as low-tax and high-tax observations. We identify low-tax firms based on their industry-adjusted pre cash ETR3 and allocate firm-year observations into 4 bins (pre taxrank) according to the quartiles of the distribution of industry-adjusted cash ETR3. Based on this, any firm observation that is aligned with the first pre taxrank is treated as a low-tax firm in a network. A strategic alliance in which at least one participant qualifies as a low-tax firm is consequently treated as a low-tax network. Firms that do not qualify as low-tax firms are treated as high-tax firms, and networks in which none of the participants is a low-tax firm are qualified as high-tax networks. Thus, our identification strategy generally follows the classification method applied by Brown and Drake (2014), who focus on board ties with tax-avoiding firms. Because we are interested in whether strategic alliances serve as channels for tax knowledge diffusion between firms, we focus on high-tax firms in our analyses. We thereby distinguish between high-tax firms that invest in low-tax networks and high-tax firms that invest in high-tax networks (Table 1 Panel C). Further excluding multiple network initiations of one firm in a single year (to rule out overweighing of a firm in the panel), our identification strategy leads us to 197 observations of networks of high-tax firms to low-tax firms and 540 observations of networks solely among high-tax firms. 


\subsection{Information on Networks and Firms}

\section{[Table 2]}

Panel A of Table 2 contains information on the distribution of pre cash ETR3 by pre taxrank, which is used to identify low-tax networks. While the mean pre cash ETR3 in the first bin of pre taxrank equals $7.08 \%$, the average rises to $63.91 \%$ in the top pre taxrank. Generally, the overlapping distribution of pre cash ETR3 by pre taxrank points towards industry specifics in the tax burdens of the firms in our sample. The overall mean of $30.66 \%$ for pre cash ETR 3 is relatively close to but below the federal corporate income tax rate of $35 \%$, which is consistent with prior research on multi-period cash effective tax rates (e.g., Dyreng, Hanlon, and Maydew (2008)). Furthermore, Panel B of Table 2 contains descriptive statistics for firm-level characteristics, separated by the classification of firms as low-tax or high-tax and by network type for high-tax firms. Panel B also includes firm-level accounting information (firm controls), which are included in our regression analyses. Following Dyreng, Hanlon, and Maydew (2010), we show information on EBITDA3, RnDExp3, AdExp3, SGA3, CapEx3, ChangeSale3, Leverage3, Cash3, MNE3, NOL3, Intangibles3, PPE3, and Size $3 .{ }^{3}$ Consistently with cash ETR3, these measures are constructed over rolling three-year periods. In Panel C of Table 2, we present information regarding the industry affiliation of networks and firms. Industry affiliation is determined on a two-digit SIC-code basis. It can be observed that the majority of networks operate in business services, while the investing firms are predominantly manufacturers and business service providers. For a better understanding of the networks in our sample, the Online Appendix provides additional information about a random selection of networks, including the date of network initiation, the investing firms, the qualification as high-tax or low-tax network and a brief deal description, which is extracted from SDC.

\footnotetext{
${ }^{3}$ All variables are defined in detail in the Appendix.
} 


\section{Methodology}

\subsection{Regression Analysis}

If engaging in low-tax strategic alliances is associated with tax knowledge diffusion, one should be able to identify increasing levels of tax planning at high-tax firms. Nevertheless, one could not draw any inferences if the influence of a network on a firm's tax planning behavior as such were omitted. Consequently, our main variable of interest hightolow is constructed as an indicator variable to distinguish between high-tax firms that enter into high-tax networks (hightolow $=0$ ) and high-tax firms that engage in low-tax networks (hightolow $=1$ ). By running our regression among high-tax firms, hightolow isolates the incremental effect a low-tax network exerts on the high-tax firm's Tax Knowledge:

Tax Knowledge $e_{i, t=1}$

$$
\begin{aligned}
& =\beta_{0}+\boldsymbol{\beta}_{\mathbf{1}} \text { hightolow }_{\boldsymbol{i}, \boldsymbol{t}=\mathbf{1}}+\sum_{n} \beta_{n} \text { partner controls }{ }_{i, t=1}^{n} \\
& +\sum_{l} \beta_{l} \text { network controls }{ }_{i, t=1}^{l}+\sum_{k} \beta_{k} \text { firm controls }_{i, t=1}^{k} \\
& +\delta_{\text {ind }}+\tau_{t}+\varepsilon_{i, t} .
\end{aligned}
$$

By using indicator notation (hightolow), the coefficient estimate describes the effect from moving from one condition to the other. As we use a three-year rolling specification of a firm's cash effective tax rate (pre cash ETR3) for identification purposes, we primarily measure Tax Knowledge by cash ETR3. Consistently, Kim et al. (2019) suggest that firms are able to adjust their tax planning behavior within three years. Consequently, the coefficient estimate for hightolow would load negatively, if strategic alliances served as channels for tax knowledge diffusion. To alleviate concerns about interpreting a level-based dependent variable, we also construct the change-indicating variable delta cash ETR3, which is cash ETR3 $\left[t_{1} ; t_{3}\right]$ scaled by pre cash ETR3 $\left[t_{-2} ; t_{0}\right]$. Given a suggested average life span for strategic alliances of five years (Chan et al., 1997), we also measure Tax Knowledge as cash ETR5 and delta cash ETR5.

[Figure 3] 
Because strategic alliances go beyond bringing together high-tax and low-tax firms, we include vectors of variables on partner \& network controls in our main regression model. From Compustat data, we can infer whether network participants share an audit firm in the year of network initiation (SameAuditor). Furthermore, we hand collect the geographical distance (as the crow flies) between the zip codes of the network participants' headquarters to control for the potential impact of geographical proximity in tax knowledge diffusion (Proximity). We normalize Proximity between 1 for the closest and 0 for the farthest distance, which allows us to interpret the sign of the coefficient in agreement with the sign of a potential indicator variable for a geographical linkage (as, for instance, in Brown (2011)). In our main regression, we do not include an indicator for firms belonging to the same industry (SameInd), as we include industry fixed effects $\left(\delta_{\text {ind }}\right)$. Generally, business activities in a strategic alliance are in no way limited and could thus exert influence on the options of tax planning that are available for a network participant. Therefore, we are interested in the main business purpose of a strategic alliance (network controls). To derive this, we apply basic textual analysis. For illustration purposes, the word cloud depicted in Figure 3 shows the 50 most common words used in SDC's deal descriptions of hightolow networks. By systematically searching through the deal descriptions, we identify PurposeWholesale, PurposeRnD, PurposeLicensing, PurposeService, PurposeMarketing, PurposeSupply, and PurposeManufacturing as network activities, create respective indicator variables at the individual network level, and include these network controls in equation (3). ${ }^{4}$ Furthermore, we control for within-firm determinants of tax planning by including a vector of firm controls. Thereby, we follow Dyreng, Hanlon, and Maydew (2010) and include EBITDA3, RnDExp3, AdExp3, SGA3, CapEx3, ChangeSale3, Leverage3, Cash3, MNE3, NOL3, Intangibles3, PPE3, and Size3. Consistent with cash ETR3, these measures are constructed over rolling three-year periods. The Appendix includes a complete list of variable definitions. In addition to industry fixed effects $\left(\delta_{\text {ind }}\right)$, we include year fixed effects $\left(\tau_{t}\right)$ and cluster standard errors at the firm level (Petersen, 2009). ${ }^{5}$

\footnotetext{
${ }^{4}$ The maximum correlation between hightolow and one of the network controls is with PurposeWholesale $(=0.0930$, not tabulated).

${ }^{5}$ The sign and overall significance of our main variable of interest are not sensitive to design choices regarding fixed effects or clustering of standard errors.
} 


\subsection{Matched Panel: Difference-in-Differences}

The regression model in equation (3) allows us to directly align tax knowledge diffusion, which should occur over time, with the year of network initiation. This approach allows us to easily account for partner \& network controls, although it condenses our panel to a cross section. An alternative approach for identifying tax knowledge diffusion is to maintain the panel structure of our data and apply a DiD methodology. In this model, treatment is generally in alignment with hightolow. Additionally, we create an embargo period of eight years around a hightolow-observation, during which a firm may not enter into an additional network. The embargo period contains the three years preceding and five years subsequent to network initiation. Our sample allows firms to enter into a network at any point in time of their discretion. We therefore compose a matched panel by matching control observations (hightolow $=0)$ to treatment observations (hightolow $=1$ ) based on year and industry affiliation. As we no longer exploit cross-sectional but panel data, we adjust dependent and control variables from multi-period measures to their single-year versions:

$$
\begin{aligned}
\operatorname{cash~ETR~}_{i, t}= & \beta_{0}+\beta_{1} \text { treated }_{i}+\beta_{2} \text { post }_{t}+\boldsymbol{\beta}_{3} \text { treated } * \text { post }_{i, t} \\
& +\sum_{k} \beta_{k} \text { firm controls }_{i, t}^{k}+\delta_{i n d}+\varepsilon_{i, t} .
\end{aligned}
$$

In this model, treated measures the baseline difference in cash ETR that is not due to the presence of the treatment. The parameter post captures changes in cash ETR from before to after treatment. The parameter of interest is the interaction treated $*$ post. It measures the effect on cash ETR that is due to the treatment (i.e., low-tax network of high-tax firm). We include industry fixed effects and the annual measures of firm controls as defined in the Appendix. Again, we base our inferences on standard errors clustered at the firm level (Petersen, 2009).

\subsection{Descriptive Analysis}

A firm's decision to engage in a network is intentional and not random, which could lead to biased sample selection. Nevertheless, it is important to note that our study does not compare network firms with non-network firms but instead focuses on a within-comparison of network firms. Nevertheless, once a firm experiences a knowledge spillover via a low-tax network, engaging in subsequent networks 
could, to some extent, also depend on an expected learning effect. Our sample could thus be nonrandomly selected, leading to concerns about endogenous treatment assignment (with regard to scholars on strategic alliances, see Carpenter, Li, and Jiang (2012)). One may account for this empirically by constructing a two-stage estimator (Heckman, 1979). Identifying valid covariates, which predict treatment assignment while having no direct impact on the dependent variable, is, however, difficult (Bodnaruk, Massa, and Simonov, 2013; Chan et al., 1997; McGuire, Omer, and Wang, 2012). Following the recommendation by Lennox, Francis, and Wang (2012), we therefore want to highlight that our study potentially has an endogeneity problem that could affect inferences from OLS regressions. However, if tax planning were an endogenous choice based on having high effective tax rates prior to engaging in tax planning (Dyreng, Hanlon, and Maydew, 2008), tax planning research would generally face endogeneity concerns. Additionally, prior research indicates that firms consider expected high taxation, measured as country-level corporate income tax rate, in the host country of a strategic alliance to be acceptable (i.e., positively associated) when forming an international network (Owen and Yawson, 2013). For further mitigation purposes, we conduct a thorough descriptive analysis. As in our regression analyses, we analyze changes in the tax planning behavior of high-tax firms in strategic alliances with low-tax firms in comparison to high-tax firms in strategic alliances with high-tax firms. We start our descriptive analysis by comparing pre cash ETR $3\left[t_{-2} ; t_{0}\right]$ between the two groups. We then focus on our primary measure for Tax Knowledge in the year of network initiation, cash ETR3 $\left[t_{1} ; t_{3}\right]$, and test the significance of differences between the groups and within-group change. We then analyze the difference in the within-group change by applying a z test following Paternoster et al. (1998):

$$
z=\frac{b_{1}-b_{2}}{\sqrt{S E b_{1}^{2}+S E b_{2}^{2}}}
$$

We also focus on an analysis of the development of Tax Knowledge for intensified networking by firms in our sample. We thereby test for the existence of a gradual learning effect. 


\section{Results \& Discussion}

\subsection{Descriptive Insights}

\section{[Table 3]}

The results of our descriptive analysis are depicted in Table 3. In Panel A, we compare changes in Tax Knowledge between and within groups. Interestingly, the mean of pre cash ETR3 is very similar for high-tax firms in the period before investing in low-tax or high-tax networks, with $38.96 \%$ and $39.35 \%$, respectively ( $\mathrm{p}$-value of difference 0.8613 ). This alleviates concerns about analyzing level measures of Tax Knowledge in equation (3). It also indicates that low-tax firms do not tend to stay among themselves by engaging in strategic alliances with sophisticated tax planners. For periods subsequent to the initiation of a network by high-tax firms, the distribution of cash ETR3 points towards a completely different direction. While observations of hightolow $=1$ are accompanied with a mean cash ETR3 of $27.55 \%$, networks solely among high-tax firms (hightolow $=0$ ) are aligned to an average cash ETR3 of $32.82 \%$. The respective difference of $5.27 \%$ is also highly significant (p-value 0.0065). Generally, we observe substantial reductions in cash effective tax rates for both groups (withingroup change), each being highly significant ( $\mathrm{p}$-values $<0.0000)$. These decreases could comprise reversion to the mean. However, this would not explain differences in the development between the groups. We therefore test whether the difference in the within-group change of 4.88 percentage points is significant and find it to be so (z-statistic -1.6994). In Panel B, we compare the development of cash ETR3 for high-tax firms' involvement in low-tax and high-tax networks with a growing number of networks. In this test, we again observe lower levels of cash ETR3 for high-tax firms in low-tax networks, with differences increasing in intensified networking. Although our descriptive analysis does not allow us to include further covariates, we interpret our findings to be consistent with the notion of strategic alliances serving as channels for tax knowledge diffusion. Therefore, we are interested in whether multivariate regression results further support this notion. 


\subsection{Regression Results}

\section{[Table 4]}

\subsubsection{Multivariate Regression}

The main variable of interest in our regression analysis is hightolow because it isolates the incremental effect a low-tax network exerts on a high-tax firm's Tax Knowledge. In Panel A of Table 4, we show multi-period specifications of Tax Knowledge for equation (3) with cash ETR3, delta cash ETR3, cash ETR5 and delta cash ETR5. By observing multi-period measures, we can link our inferences to the period of network initiation. For brevity, we report only the coefficient estimates for hightolow and partner controls. Throughout all specifications, the estimate for hightolow is negative and highly significant. In the specification with cash ETR3 as the dependent variable, the estimate for hightolow has a magnitude of -0.0480 ( $\mathrm{p}$-value 0.0103 ), which is consistent with our descriptive inferences in terms of direction and magnitude. Because an overall network effect is absorbed by including high-tax firms in our regression and because the covariates on partner, network \& firm controls account for a broad range of alternative explanations, we find it plausible to associate the (relative) increase in tax planning practices for high-tax firms in low-tax networks to be induced by the presence of the low-tax firm in the network. Extending equation (3) to a change-indicating variable, delta cash ETR3, yields the same implications (p-value 0.0061). Furthermore, we extend our model to cash ETR5 and delta cash ETR5, which are constructed identically to cash ETR3 and delta cash ETR3 but over five years subsequent to and including the year of network initiation as the dependent variables. The results for these specifications imply a slightly smaller magnitude (coefficient estimate for (delta) cash ETR5 is $-0.0376(-0.1229))$ in effects but are both negative and highly significant. Interestingly, the estimates for our partner controls, namely, Proximity and SameAuditor, do not surpass the usual levels of significance. In several additional analyses (see Section 6), we focus on the interactions of hightolow and partner controls to align our findings with prior research. Overall, our findings in Panel A convey that decreases in cash taxes paid are driven by the partner firm's tax planning behavior. 


\subsubsection{Difference-in-Differences}

[Figure 4]

Panel B of Table 4 shows the results for our DiD analysis from equation (4). Any DiD specification relies on the parallel trend assumption. Otherwise, one could not empirically identify the posttreatment outcome absent the treatment. Usually, the parallel trend assumption is graphically examined by observing pretreatment trends of the dependent variable among the treatment and control groups. Accordingly, Panel A of Figure 4 provides visual evidence that the trends of cash ETR are parallel for treatment and control firms prior to the treatment (hightolow $=1$ ). Consistent with our analysis on the full sample, it can also be observed that the pretreatment levels of cash ETR are very similar for the treated and untreated firms in the matched panel. While a direct empirical test for the parallel trend assumption is not possible, Patel and Seegert (2015) developed an approach to alleviate concerns about potential confounding factors. They suggest regressing the treatment indicator, time fixed effects and the interaction of the treatment indicator and time fixed effects on the dependent variable:

$$
\text { cash ETR }_{i, t}=\alpha+\text { treated }_{i}+\tau_{t}+\tau_{t} * \text { treated }_{i}+\varepsilon_{i, t} .
$$

They argue that failure to reject that the coefficient estimates for the interaction terms for $\tau_{t} *$ treated $_{i}$ are jointly zero in the pretreatment period supports the parallel trend assumption. In Panel B of Figure 4, we therefore present the coefficient and the $95 \%$ confidence interval of the interaction of the treatment indicator and time fixed effects from equation (6) for the pretreatment years. First, none of the individual coefficients are significantly different from zero. More importantly, however, the p-value of the common trend test (the coefficients on $\tau_{t} *$ treated $_{i}$ are jointly zero during pretreatment $)$ is far beyond the usual levels of significance $(\mathrm{p}=0.7427)$. Consequently, we are able to provide visual and statistical evidence for the parallel trend assumption.

In Panel B of Table 4, we depict several specifications of equation (4) with varying levels of firm controls and industry fixed effects $\left(\delta_{\text {ind }}\right)$. The estimate for the interaction of treated $*$ post is negative and significant throughout all these specifications. Consequently, we find a negative cash ETR response to low-tax networks in comparison to high-tax networks for high-tax firms. Taken together, 
the results from our descriptive and regression analyses are consistent with strategic alliances serving as channels through which tax knowledge diffuses between firms.

\subsubsection{Adjustment Speed}

We are further interested in how fast high-tax firms are able to adjust their tax planning behavior when cooperating with low-tax firms. Therefore, we estimate five specifications of equation (4). We extend the posttreatment period by one year with each specification. Thus, we notate post $=1$ only for the year of network initiation $\left[t_{1}\right]$ first, and finish with post equaling one for the complete embargo period $\left[t_{1} ; t_{5}\right]$. The coefficient estimates for treatment $*$ post thus present the cumulative adjustment of a high-tax firm's tax planning behavior with progressing time ( $t_{1}$ to $\left.t_{5}\right)$ when cooperating with low-tax firms (i.e. adjustment speed). The results for this analysis are presented in Panel C of Table 4. In concordance with theory suggesting that (tax) knowledge spillovers are likely to occur over time, the coefficient estimate for treatment $*$ post is not significant when the posttreatment period is limited to the year of network initiation. The coefficient estimate for the interaction, however, turns significant when post equals one for $t_{1}$ and $t_{2}$. Furthermore, the estimated effect continues to be significant when extending the posttreatment period to $t_{3}, t_{4}$ and $t_{5}$. Consequently, we assess high-tax firms on average to be able to adjust their tax planning behavior within two years of network initiation. These findings are consistent with recent research by Kim et al. (2019), who suggest that firms generally should be able to adjust their tax planning behavior within three years and that high-tax firms may increase their tax planning behavior even faster. Additionally, our results suggest that a firm's adjustment of its tax planning behavior, once implemented, stays constant over subsequent years. 


\section{Additional Analyses}

\section{[Table 5]}

Thus far, we have considered the overall implications of low-tax networks for high-tax firms. We are also interested in the characteristics of network participants, which could intensify or mitigate the identified learning effects. First, prior research provides mixed evidence regarding the role of auditors in tax knowledge diffusion (Klassen, Lisowsky, and Mescall, 2016; Lim et al., 2018; McGuire, Omer, and Wang, 2012). Furthermore, Brown (2011) and Brown and Drake (2014) hypothesized that geographical proximity and identical industry affiliation of the participants could enhance knowledge diffusion.

In Panel A of Table 5, we compare two subsamples of networks, following the identification strategy of Brown (2011). One group consists of firms with their headquarters located in the same region, as defined by the Bureau of Economic Analysis (SameBEARegion =1) ${ }^{6}$ The other group consists of firms with headquarters located in different BEA regions in the year of network initiation (SameBEARegion = 0). The intuition behind this approach is that shared membership in a geographical region should allow higher levels of interfirm interaction. We run specifications of equation (3) with (delta) cash ETR3 as the dependent variable and are interested in the interaction terms of hightolow $*$ SameBEARegion because these coefficient estimates comprise the incremental influence of geographical proximity on tax knowledge diffusion via low-tax networks. However, we observe a significant coefficient estimate of the main effect of hightolow. Neither SameBEARegion nor the interaction of the two are significantly different from zero. While this finding is generally consistent with the inferences by Brown (2011) on regional linkages, Cen et al. (2018) report that the correlation of effective tax rates is stronger for members of a supply chain that are located within the same geographical region.

In their hypothesis development, Brown and Drake (2014) argue that similar background knowledge and similar capabilities should have a positive impact on tax knowledge diffusion. They suggest that firms with the same industry affiliation share the same operating environment, which they expect to

\footnotetext{
${ }^{6}$ The respective BEA regions are Far West, Great Lakes, Mideast, New England, Plains, Rocky Mountains, Southeast and Southwest.
} 
enhance the effect. However, the results from comparing intra- and interindustry board ties fall short of their expectation. To test the potential effect of shared industry affiliation, we construct, coinciding with our approach in Panel A, two subsamples. One group consists of network participants who share industry affiliation (SameInd $=1$ ), and the other group consists of firms with different industry affiliations (SameInd $=0$ ). Consistent with Brown and Drake (2014) and in line with our inferences from geographical proximity, we cannot reject that the interactions of hightolow and SameInd are significantly different from zero. Although this finding seems somewhat counterintuitive, we want to highlight that tax shelters are often repetitive among firms, not limited by industry barriers and serve as mass market tax saving ideas (Lisowsky, 2010). However, we observe that the main effect of SameInd is negative and significant (p-value 0.0530 (0.0735) in the (delta) cash ETR3 specification).

Finally, we extend our analysis of network heterogeneity to examine the role of shared audit firms. Therefore, we analyze whether firms share an audit firm in the year of network initiation. Based on this, we construct an indicator variable (SameAuditor) and interact it with hightolow. In specifications of equation (3) with cash ETR3 and delta cash ETR3 as dependent variables, the interaction terms for hightolow $*$ SameAuditor respectively approach common levels of statistical significance. Our inferences take their place alongside a range of mixed inferences concerning auditors' impact on tax knowledge diffusion. While Brown (2011) does not find significant tax shelter adoption via shared audit firms, and Klassen, Lisowsky, and Mescall (2016) show that less tax aggressiveness in the past is associated with the auditor preparing a firm's tax return, Lim et al. (2018), and Cen et al. (2018) suggest that common auditors facilitate tax planning diffusion.

Overall, the results presented in Table 5 might easily be subject to misinterpretation. We do not posit that industry affiliation, auditor ties or geographical proximity do not have an incremental effect on how tax knowledge diffuses between firms. We are interested solely in whether partner heterogeneity accelerates or alleviates tax knowledge diffusion for high-tax firms that invest in low-tax networks. It appears that tax knowledge diffusion via strategic alliances is rather unaffected by such heterogeneity. 


\section{Robustness Checks}

In this section, we examine the robustness of our primary findings with regard to alternative explanations and potential concerns about our identification strategy. Thereby, we rule out the possibility that our findings are unrelated to tax knowledge diffusion.

\subsection{Alternative Explanations}

[Table 6]

Applying three-year rolling measures of cash effective tax rates would systematically exclude from our sample network-firm-observations that occur at the first, second, penultimate and final firm-years of a network participant. For identification purposes, we substitute [pre]cash ETR3 with [pre] cash ETR(2). However, it is possible that strategic alliances serve as preliminary ties between successive acquirers and targets (Ishii and Xuan, 2014; Porrini, 2004). Survivorship bias could thus exert influence on our inferences. Consequently, we present a specification of equation (3) in Panel A of Table 6 in which we exclude nonsurvivors (i.e., firms with a network-firm-observations within the last two years of their presence in our panel) from the analysis. In this model, we still find the loading of hightolow to be significant (p-value 0.0571 ) and the economic magnitude to be consistent with our primary findings. This result indicates that our inferences are robust to survivorship bias.

Another alternative explanation of our findings could be that the difference in the levels of Tax Knowledge between the two groups in our sample is not induced by tax knowledge diffusion from low-tax firms to high-tax firms but by increases in cash ETR3 for high-tax firms in high-tax networks.

\section{[Figure 5]}

Figure 5 depicts a kernel density plot of the distribution of delta cash ETR3 for all high-tax firms. The dotted line at $x=1$ indicates the threshold between a decrease and an increase for cash ETR 3 relative to pre cash ETR3. It can be observed that part of the high-tax firm population experiences increases in cash ETR3, which would, to some extent, not be consistent with knowledge diffusion. In Panel B of Table 6, we provide a specification of equation (3) in which we control for increases in cash ETR3 by 
including only observations of delta cash ETR3 that are equal to or below the threshold of one. Again, our results indicate a negative and significant coefficient estimate for hightolow. Consequently, we are confident that our inferences are based on tax knowledge diffusion via low-tax networks rather than on increases in cash ETR3 in the control group.

While we find high-tax firms to receive tax knowledge via low-tax networks, we have not considered the tax position of low-tax firms. Correspondingly to high-tax firms, low-tax firms can be bound to either high-tax firms or low-tax firms. Intuitively, there is little reason to expect incremental or even "negative" tax knowledge spillovers for low-tax firms bound to high-tax firms. To empirically control for this notion, we construct lowtohigh, which is an indicator that equals one for low-tax firms in networks with high-tax firms and zero for low-tax firms in low-tax networks. The results for this specification of equation (3) are presented in Panel C of Table 6. The coefficient estimate for lowtohigh is far beyond common levels of significance, with a p-value of 0.9961 . This finding further supports our inferences of tax knowledge diffusion occurring among high-tax firms.

Since effective tax rates are influenced by tax payments and profitability, changes in cash ETR 3 could be solely income induced. This would to some extent speak against identifying tax knowledge diffusion. To account for this concern, we construct ChangeEBITDA3, which is the annual average growth rate in EBITDA from $t_{1}$ to $t_{3}$ (geometric mean). We then run equation (3) with ChangeEBITDA3 as the dependent variable and find the coefficient estimate for hightolow to be nonsignificant (p-value 0.6569) and of small economic magnitude (Panel D of Table 6). From this, it follows that the identified effects are not linked to profitability.

[Figure 6]

Finally, our inferences could be explained by aspects of firm structure. Strategic alliances could, for instance, be formed around the same time a firm returns to profitability. Additionally, networks could open foreign markets for the participants, which would allow profit shifting to tax havens. However, there is little reason to expect high-tax firms to experience these changes in low-tax networks (hightolow contains the incremental effect on a firm's tax position). Nevertheless, we depict the (threeyear) annual average growth rates for foreign income (ChangePIFO3) and tax loss carry forward 
(ChangeNOL3) separated by hightolow in Figure 6. It can be observed that the distributions are nearly identical. We interpret this as follows. Low-tax networks are channels for tax knowledge diffusion from low-tax firms to high-tax firms. They are, however, not necessarily accompanied by incremental structural changes for the group of "treated" firms. This complicates the identification of mechanisms through which tax knowledge diffuses, as this process seems to be driven by soft factors rather than by exposing itself in (one) explicit accounting measure(s) of firm structure.

\subsection{Alternative Identification Strategy}

[Table 7]

There are some judgment calls involved in classifying strategic alliances as high-tax- and low-tax networks and including an indicator variable in the respective regression. Therefore, we provide a modified model in which we regress the industry-adjusted pre cash ETR3 $\left[t_{-2} ; t_{0}\right]$ of a firm and of its partner on the firm's cash ETR $3\left[t_{1} ; t_{3}\right]$ :

$$
\begin{aligned}
& \text { cash ETR } 3_{i, t=1}=\beta_{0}+\beta_{1} O w n_{-} i n d \_a d j \_p r e \_c a s h \_E T R 3_{i, t=0} \\
& +\beta_{2} P a r t n e r_{-} i n d \_a d j_{-} p r e_{-} c a s h \_E T R 3_{i, t=0} \\
& +\sum_{n} \beta_{n} \text { partner controls } s_{i, t=1}^{n} \\
& +\sum_{l} \beta_{l} \text { network controls }{ }_{i, t=1}^{l} \\
& +\sum_{k} \beta_{k} \text { firm controls } s_{i, t=1}^{k}+\varepsilon_{i, t} \text {. }
\end{aligned}
$$

Since we use industry-adjusted measures of cash ETR3 in this model, we do not insert industry fixed effects. However, we include the indicator SameInd in addition to the partner controls (SameAuditor, Proximty). If the partner firm's tax position were correlated with the firm's own levels of tax planning, one would find a positive coefficient estimate of Partner_ind_adj_pre_cash_ETR3. In a first specification of equation (7), we include network-firm-observations of low-tax firms and hightax firms. The results are depicted in Panel A of Table 7. While we observe a positive and highly significant coefficient estimate of Own_ind_adj_pre_cash_ETR3, Partner_ind_adj_pre_cash_ETR3 is not significant. The latter finding is, however, little surprising 
given the inference that low-tax firms are rather unaffected by their partner firms' tax positions (Table 6 Panel C). Therefore, we include network-firm-observations of high-tax firms in a second specification of equation (7). In this model, the coefficient estimate of Partner_ind_adj_pre_cash_ETR3 is significant (p-value 0.0936). Consistent with the findings from our main analysis and with the notion of tax knowledge diffusion via strategic alliances, we find a positive association between partner firms' cash effective tax rates.

\section{Conclusion}

The purpose of this study is to further shed light on channels through which tax knowledge diffuses between firms. Despite solid insights on within-firm determinants of corporate tax planning, research on cross-firm connections in this field is still developing. We contribute to this emerging literature by being the first to identify strategic alliances as channels of tax knowledge diffusion between firms. Using data on strategic alliances between publicly traded US firms, we are able to distinguish between networks that bring together high-tax and low-tax firms and networks that are established among hightax firms respectively. Our results suggest that strategic alliances provide channels through which tax knowledge diffuses from low-tax firms to undersheltered firms. This identified channel should interest corporate executives, regulators, and researchers because the perception and valuation of the documented spillovers highly depend on the respective point of view.

Although prior research has dedicated substantial attention to corporate cooperation and individual firms' tax planning, there are a number of unanswered questions regarding the interplay of the two. Primarily, we encourage research on the actual mechanisms of tax knowledge diffusion. Furthermore, it remains unclear whether the tax position of a potential network partner influences the decision of a firm to invest in a specific strategic alliance. Our hope is that our study enhances interdisciplinary research in accounting and management. 


\section{References}

Acemoglu, D., Dahleh, M.A., Lobel, I., Ozdaglar, A., 2011. Bayesian Learning in Social Networks. The Review of Economic Studies 78 (4), 1201-1236.

Anand, B.N., Khanna, T., 2000. Do Firms Learn to Create Value? The Case of Alliances. Strategic Management Journal 21 (3), 295-315.

Aobdia, D., 2015. Proprietary information spillovers and supplier choice: evidence from auditors. Review of Accounting Studies 20 (4), 1504-1539.

Barrios, J.M., Gallemore, J., 2018. Tax-Related Human Capital: Evidence from Employee Movements. SSRN Electronic Journal.

Blonski, M., 1999. Social learning with case-based decisions. Journal of Economic Behavior \& Organization 38 (1), 59-77.

Bodnaruk, A., Massa, M., Simonov, A., 2013. Alliances and corporate governance. Journal of Financial Economics 107 (3), 671-693.

Boone, A.L., Ivanov, V.I., 2012. Bankruptcy spillover effects on strategic alliance partners. Journal of Financial Economics 103 (3), 551-569.

Brown, J.L., 2011. The Spread of Aggressive Corporate Tax Reporting: A Detailed Examination of the Corporate-Owned Life Insurance Shelter. The Accounting Review 86 (1), 23-57.

Brown, J.L., Drake, K.D., 2014. Network Ties Among Low-Tax Firms. The Accounting Review 89 (2), 483-510.

Cai, Y., Dhaliwal, D.S., Kim, Y., Pan, C., 2014. Board interlocks and the diffusion of disclosure policy. Review of Accounting Studies 19 (3), 1086-1119.

Cai, Y., Kim, Y., Park, J.C., White, H.D., 2016. Common auditors in M\&A transactions. Journal of Accounting and Economics 61 (1), 77-99.

Cai, Y., Sevilir, M., 2012. Board connections and M\&A transactions. Journal of Financial Economics 103 (2), 327-349.

Carpenter, M.A., Li, M., Jiang, H., 2012. Social Network Research in Organizational Contexts. Journal of Management 38 (4), 1328-1361.

Cen, L., Maydew, E.L., Zhang, L., Zuo, L., 2017. Customer-supplier relationships and corporate tax avoidance. Journal of Financial Economics 123 (2), 377-394.

Cen, L., Maydew, E.L., Zhang, L., Zuo, L., 2018. Tax Planning Diffusion Along the Supply Chain. SSRN Electronic Journal.

Chan, S.H., Kensinger, J.W., Keown, A.J., Martin, J.D., 1997. Do strategic alliances create value? Journal of Financial Economics 46 (2), 199-221.

Chen, J., King, T.-H.D., Wen, M.-M., 2015. Do joint ventures and strategic alliances create value for bondholders? Journal of Banking \& Finance 58, 247-267.

Desai, M.A., Foley, C.F., Hines, J.R., 2004. The costs of shared ownership: Evidence from international joint ventures. Journal of Financial Economics 73 (2), 323-374.

Dhaliwal, D.S., Lamoreaux, P.T., Litov, L.P., Neyland, J.B., 2016. Shared auditors in mergers and acquisitions. Journal of Accounting and Economics 61 (1), 49-76.

Di Maggio, M., Franzoni, F., Kermani, A., Sommavilla, C., 2019. The relevance of broker networks for information diffusion in the stock market. Journal of Financial Economics 134 (2), 419-446.

Dyer, J.H., Hatch, N.W., 2006. Relation-specific capabilities and barriers to knowledge transfers: creating advantage through network relationships. Strategic Management Journal 27 (8), 701-719.

Dyreng, S., Hanlon, M., Maydew, E.L., 2018. When Does Tax Avoidance Result in Tax Uncertainty? The Accounting Review (forthcoming).

Dyreng, S., Maydew, E.L., 2017. Virtual Issue on Tax Research Published in the Journal of Accounting Research. SSRN Electronic Journal. 
Dyreng, S.D., Hanlon, M., Maydew, E.L., 2008. Long-Run Corporate Tax Avoidance. The Accounting Review 83 (1), 61-82.

Dyreng, S.D., Hanlon, M., Maydew, E.L., 2010. The Effects of Executives on Corporate Tax Avoidance. Accounting Review 85 (4), 1163-1189.

Erickson, M., 1998. The Effect of Taxes on the Structure of Corporate Acquisitions. Journal of Accounting Research 36 (2), 279.

Erickson, M.M., Wang, S.-w., 1999. Exploiting and Sharing Tax Benefits: Seagram and DuPont. The Journal of the American Taxation Association 21 (2), 35-54.

Fiol, C.M., Lyles, M.A., 1985. Organizational Learning. Academy of Management Review 10 (4), $803-$ 813.

Frey, L., 2018. Tax certified individual auditors and effective tax rates. Business Research 11 (1), $77-$ 114.

Gale, D., Kariv, S., 2003. Bayesian learning in social networks. Games and economic behavior 45 (2), 329-346.

Gallemore, J., Gipper, B., Maydew, E.L., 2018. Banks as Tax Planning Intermediaries. Journal of Accounting Research 126, 1841.

Gallemore, J., Maydew, E.L., Thornock, J.R., 2014. The Reputational Costs of Tax Avoidance. Contemporary Accounting Research 31 (4), 1103-1133.

Graham, J.R., Hanlon, M., Shevlin, T., Shroff, N., 2017. Tax Rates and Corporate Decision-making. The Review of Financial Studies 30 (9), 3128-3175.

Guenther, D.A., Matsunaga, S.R., Williams, B.M., 2017. Is Tax Avoidance Related to Firm Risk? The Accounting Review 92 (1), 115-136.

Hanlon, M., Heitzman, S., 2010. A review of tax research. Journal of Accounting and Economics 50 (23), 127-178.

Hanlon, M., Slemrod, J., 2009. What does tax aggressiveness signal? Evidence from stock price reactions to news about tax shelter involvement. Journal of Public Economics 93 (1-2), 126-141.

Heckman, J.J., 1979. Sample Selection Bias as a Specification Error. Econometrica 47 (1), 153.

Higgins, M.J., Rodriguez, D., 2006. The outsourcing of R\&D through acquisitions in the pharmaceutical industry. Journal of Financial Economics 80 (2), 351-383.

Hoppe, T., Schanz, D., Sturm, S., Sureth-Sloane, C., 2019. Measuring Tax Complexity Across Countries: A Survey Study on MNCs. Accounting for Transparency Working Papers No. 5.

Hundsdoerfer, J., Jacob, M., 2018. Corporate Taxes and Firms' Cost Behavior: The Role of Conforming Tax Planning. Working Paper.

Inkpen, A.C., 2000. Learning Through Joint Ventures: A Framework Of Knowledge Acquisition. Journal of Management Studies 37 (7), 1019-1044.

Inkpen, A.C., 2008. Knowledge transfer and international joint ventures: the case of NUMMI and General Motors. Strategic Management Journal 29 (4), 447-453.

Isaksson, O.H.D., Simeth, M., Seifert, R.W., 2016. Knowledge spillovers in the supply chain: Evidence from the high tech sectors. Research Policy 45 (3), 699-706.

Ishii, J., Xuan, Y., 2014. Acquirer-target social ties and merger outcomes. Journal of Financial Economics 112 (3), 344-363.

Jiang, X., Bao, Y., Xie, Y., Gao, S., 2016. Partner trustworthiness, knowledge flow in strategic alliances, and firm competitiveness: A contingency perspective. Journal of Business Research 69 (2), 804-814.

Kale, P., Singh, H., Perlmutter, H., 2000. Learning and Protection of Proprietary Assets in Strategic Alliances: Building Relational Capital. Strategic Management Journal 21 (3), 217-237.

Khanna, T., Gulati, R., Nohria, N., 1998. The Dynamics of Learning Alliances: Competition, Cooperation, and Relative Scope. Strategic Management Journal 19 (3), 193-210. 
Kim, J., McGuire, S.T., Savoy, S., Wilson, R., Caskey, J., 2019. How Quickly Do Firms Adjust to Optimal Levels of Tax Avoidance? Contemporary Accounting Research 36 (3), 1824-1860.

Klassen, K.J., Lisowsky, P., Mescall, D., 2016. The Role of Auditors, Non-Auditors, and Internal Tax Departments in Corporate Tax Aggressiveness. The Accounting Review 91 (1), 179-205.

Kogut, B., Singh, H., 1988. The Effect of National Culture on the Choice of Entry Mode. Journal of International Business Studies 19 (3), 411-432.

Lennox, C.S., Francis, J.R., Wang, Z., 2012. Selection Models in Accounting Research. The Accounting Review 87 (2), 589-616.

Lim, C.Y., Shevlin, T.J., Wang, K., Xu, Y., 2018. Tax Knowledge Diffusion Through Individual Auditor Network Ties: Evidence from China. SSRN Electronic Journal.

Lindsey, L., 2008. Blurring Firm Boundaries: The Role of Venture Capital in Strategic Alliances. The Journal of Finance 63 (3), 1137-1168.

Lisowsky, P., 2010. Seeking Shelter: Empirically Modeling Tax Shelters Using Financial Statement Information. The Accounting Review 85 (5), 1693-1720.

McGuire, S.T., Omer, T.C., Wang, D., 2012. Tax Avoidance: Does Tax-Specific Industry Expertise Make a Difference? The Accounting Review 87 (3), 975-1003.

Meier, M., 2011. Knowledge Management in Strategic Alliances: A Review of Empirical Evidence. International Journal of Management Reviews 13 (1), 1-23.

Mohanram, P., Nanda, A., 1996. When do Joint Ventures create value? Academy of Management Proceedings 1996 (1), 36-40.

Nonaka, I., 1994. A Dynamic Theory of Organizational Knowledge Creation. Organization Science 5 (1), 14-37.

Owen, S., Yawson, A., 2013. Information asymmetry and international strategic alliances. Journal of Banking \& Finance 37 (10), 3890-3903.

Patel, E., Seegert, N., 2015. Using Strategic Interactions in Investment Decisions to Increase the Efficiency of Tax Policy. SSRN Electronic Journal.

Paternoster, R., Brame, R., Mazerolle, P., Piquero, A., 1998. Using The Correct Statistical Test For The Equality Of Regression Coefficients. Criminology 36 (4), 859-866.

Petersen, M.A., 2009. Estimating Standard Errors in Finance Panel Data Sets: Comparing Approaches. The Review of Financial Studies 22 (1), 435-480.

Porrini, P., 2004. Can a Previous Alliance Between an Acquirer and a Target Affect Acquisition Performance? Journal of Management 30 (4), 545-562.

PwC, 2018. New Entrants - New Rivals. How Germany's top companies are creating a new industry world.

Rogers, E.M., 2003. Diffusion of innovations. Free Press, New York, London, Toronto, Sydney.

Szulanski, G., 1996. Exploring Internal Stickiness: Impediments to the Transfer of Best Practice Within the Firm. Strategic Management Journal 17, 27-43.

Tørsløv, T., Wier, L., Zucman, G., 2018. The Missing Profits of Nations. National Bureau of Economic Research, Cambridge, MA.

Wilde, J.H., Wilson, R.J., 2018. Perspectives on Corporate Tax Planning: Observations from the Past Decade. The Journal of the American Taxation Association 40 (2), 63-81.

Wilson, R.J., 2009. An Examination of Corporate Tax Shelter Participants. The Accounting Review 84 (3), 969-999. 


\section{Appendix: Variable Definitions}

\section{Variable Definition (Compustat/SDC equivalent)}

\section{Network Characteristics}

\begin{tabular}{cl}
\hline \hline high-tax network & Equals 1 for networks with solely high-tax firms as participants. \\
\hline hightolow & Indicator variable; equals 1 for high-tax firms in low-tax \\
& networks; equals 0 for high-tax firms in high-tax networks; if a \\
& firm enters into multiple networks in one year, only one \\
& observation of this firm enters our sample in this year. In these \\
& cases, network selection is primarily done on a randomized basis. \\
& However, if a firm entered as high-tax firm into a low-tax network \\
& and into (a) high-tax network(s) in one year, we keep the low-tax \\
& network observation. \\
\hline low-tax network & Equals 1 for networks involving at least one low-tax firm. \\
\hline lowtohigh & Indicator variable; equals 1 for low-tax firms in high-tax \\
& networks; equals 0 for low-tax firms in low-tax networks. \\
\hline network controls & Indicator variables for the main business purpose of a network, \\
& which is derived from a network's deal description (DealText) in \\
& SDC; comprises PurposeWholesale, PurposeRnD, \\
& PurposeLicensing, PurposeService, PurposeMarketing, \\
& PurposeSupply and PurposeManufacture; information is \\
& systematically extracted with R: dofile available upon request. \\
\hline
\end{tabular}

\section{Partner Characteristics}

\begin{tabular}{cl}
\hline \hline Proximity & $\begin{array}{l}\text { Distance (as the crow flies) between the participants of a network } \\
\text { according to the zip code of the participants headquarters } \\
\text { (addzip); collected from freemaptools.com; normalized between } \\
1 \text { and 0 for closest (same addzip) and farthest distance. }\end{array}$ \\
\hline SameAuditor & $\begin{array}{l}\text { Indicator variable; equals 1 when all participants of a network } \\
\text { share the same auditor firm (au) in the year of network initiation; } \\
0 \text { otherwise; by nature of construction missing for non-network- } \\
\text { firm-observations. }\end{array}$ \\
\hline SameInd & $\begin{array}{l}\text { Constructed as SameAuditor but for industry affiliation; industry } \\
\text { is classified using two-digit SIC codes (sic); see also Table 2. }\end{array}$ \\
\hline Constructed as SameAuditor; equals 1 when all network \\
participants are located in the same BEA region in the year of \\
network initiation; 0 otherwise; the respective regions, as defined \\
by the Bureau of Economic Analysis, are Far West, Great Lakes, \\
Mideast, New England, Plains, Rocky Mountains, Southeast and \\
Southwest. \\
\hline Partner controls
\end{tabular}




\section{Firm Characteristics}

$\operatorname{cash} E T R$

Cash effective tax rate; defined as cash taxes paid (txpd) divided by pre-tax income (pi) before special items (spi); special items are reset to 0 when missing; cash ETR observations with negative denominator are reset to missing; winsorized at 0 and 1 .

cash ETR3

Cash effective tax rate; defined as cash taxes paid (txpd) divided by pre-tax income (pi) before special items (spi); special items are reset to 0 when missing; numerator and denominator are constructed as the sum of the current and two subsequent years; observations with negative denominator are reset to missing; for the final (penultimate) firm-year of a firm substituted by cash $\operatorname{ETR}(2)$; winsorized at 0 and 1.

cash ETR5 Cash effective tax rate; constructed as cash ETR3, but for five years.

\begin{tabular}{|c|c|}
\hline ChangeEBITDA3 & $\begin{array}{l}\text { Three-year annual average growth rate (geometric mean) of } \\
\text { EBITDA (ebitda) }\left(\sqrt[3]{e b i t d a_{t 3} / e b i t d a_{t 1}}-1\right) \text {; reset to } 0 \text { when } \\
\text { missing. }\end{array}$ \\
\hline ChangePIFO3 & $\begin{array}{l}\text { Constructed as ChangeEBITDA3, but for foreign pre-tax income } \\
\text { (pifo). }\end{array}$ \\
\hline ChangeNOL3 & $\begin{array}{l}\text { Constructed as ChangeEBITDA3, but for tax loss carry forward } \\
\text { (tlcf). }\end{array}$ \\
\hline delta cash ETR3 & Cash ETR3 $\left[\mathrm{t}_{1} ; \mathrm{t}_{3}\right]$ scaled by pre cash ETR3 [ $\left.\mathrm{t}_{-2} ; \mathrm{t}_{0}\right]$. \\
\hline delta cash ETR5 & Cash ETR5 $\left[\mathrm{t}_{1} ; \mathrm{t}_{5}\right]$ scaled by pre cash ETR3 $\left[\mathrm{t}_{-2} ; \mathrm{t}_{0}\right]$. \\
\hline high-tax firm & $\begin{array}{l}\text { Indicator variable; equals } 1 \text { when a firm's industry adjusted pre } \\
\left.\text { cash ETR3 } \mathrm{t}_{-2} ; \mathrm{t}_{0}\right] \text { is aligned to pre taxrank }[2 ; 4] \text { (if pre taxrank }\left[\mathrm{t}_{0}\right] \\
\text { is missing, replaced by pre taxrank[t-1]);0 otherwise. }\end{array}$ \\
\hline low-tax firm & $\begin{array}{l}\text { Indicator variable; equals } 1 \text { when a firm's industry adjusted pre } \\
\text { cash ETR3 }\left[\mathrm{t}_{-} ; \mathrm{t}_{0}\right] \text { is aligned to pre taxrank }=1 \text { (if pre taxrank }\left[\mathrm{t}_{0}\right] \\
\left.\text { is missing, replaced by pre taxrank }\left[\mathrm{t}_{-}\right]\right) ; 0 \text { otherwise. }\end{array}$ \\
\hline post & $\begin{array}{l}\text { Indicator variable; equals } 0 \text { for a period of three years before } \\
\text { network initiation and } 1 \text { for a period of five years subsequent to } \\
\text { initiation and includes treatment/control observations. post } \\
\text { constitutes an embargo period during which no other hightolow } \\
\text { observation may occur. }\end{array}$ \\
\hline pre cash ETR3 & $\begin{array}{l}\text { Constructed as cash ETR3 but with numerator and denominator } \\
\text { constructed as the sum of the current and two preceding periods; } \\
\text { for first (second) firm-year of a firm substituted by pre cash } \\
\text { ETR(2). }\end{array}$ \\
\hline pre taxrank & $\begin{array}{l}\text { Allocates ranks (1-4) according to the quartiles of the distribution } \\
\text { of industry adjusted pre cash ETR3; } 1 \text { for the bottom end, } 4 \text { for } \\
\text { the top end of the distribution. }\end{array}$ \\
\hline treated & $\begin{array}{l}\text { Treatment is in alignment with hightolow (see post for embargo } \\
\text { period) and extended to pre- and post-periods. }\end{array}$ \\
\hline treated $*$ post & $\begin{array}{l}\text { Interaction of treated and post; main variable of interest in } \\
\text { difference-in-differences model. }\end{array}$ \\
\hline
\end{tabular}




\section{Firm Controls*}

\begin{tabular}{|c|c|}
\hline AdExp3 & $\begin{array}{l}\text { Advertising expense (xad) divided by net sales (sale); numerator } \\
\text { and denominator are constructed as the sum of the current and two } \\
\text { subsequent years; when missing reset to annual measure, } \\
\text { thereafter reset to } 0 \text {. }\end{array}$ \\
\hline CapEx 3 & $\begin{array}{l}\text { Reported capital expenditures (capx) divided by gross property, } \\
\text { plant, and equipment (ppegt); numerator and denominator are } \\
\text { constructed as the sum of the current and two subsequent years; } \\
\text { when missing reset to annual measure, thereafter reset to } 0 \text {. }\end{array}$ \\
\hline Cash3 & $\begin{array}{l}\text { Cash and cash equivalents (che) divided by total assets (at); } \\
\text { numerator and denominator are constructed as the sum of the } \\
\text { current and two subsequent years; when missing reset to annual } \\
\text { measure, thereafter reset to } 0 \text {. }\end{array}$ \\
\hline ChangeSale 3 & $\begin{array}{l}\text { Three-year annual average growth rate (geometric mean) of net } \\
\text { sales (sale) }\left(\sqrt[3]{\text { sale }_{t 3} / \text { sale }_{t 1}}-1\right) \text {; when missing reset to annual } \\
\text { change, thereafter reset to } 0 .\end{array}$ \\
\hline EBITDA3 & $\begin{array}{l}\text { Earnings before interest, taxes, depreciation and amortization } \\
\text { (ebitda) scaled by total assets (at); numerator and denominator are } \\
\text { constructed as the sum of the current and two subsequent years; } \\
\text { when missing reset to annual measure, thereafter reset to } 0 \text {. }\end{array}$ \\
\hline Intangibles 3 & $\begin{array}{l}\text { The ratio of intangible assets (intan) to total assets (at); numerator } \\
\text { and denominator are constructed as the sum of the current and two } \\
\text { subsequent years; when missing reset to annual measure, } \\
\text { thereafter reset to } 0 \text {. }\end{array}$ \\
\hline Leverage 3 & $\begin{array}{l}\text { The sum of long-term debt (dltt) and long-term debt in current } \\
\text { liabilities (dlc) divided by total assets (at); numerator and } \\
\text { denominator are constructed as the sum of the current and two } \\
\text { subsequent years; when missing reset to annual measure, } \\
\text { thereafter reset to } 0 \text {. }\end{array}$ \\
\hline MNE3 & $\begin{array}{l}\text { Indicator variable; equals } 1 \text { if pifo }>0 \text { (non-missing, non-zero } \\
\text { value for pre-tax income from foreign operations), } 0 \text { otherwise; } \\
\text { measured as the sum over three years. }\end{array}$ \\
\hline NOL3 & $\begin{array}{l}\text { Indicator variable equals } 1 \text { if tlcf }>0 \text { (non-missing, non-zero value } \\
\text { of tax loss carry forward), } 0 \text { otherwise; measured as the sum over } \\
\text { three years. }\end{array}$ \\
\hline PPE3 & $\begin{array}{l}\text { Gross property, plant, and equipment (ppegt) divided by total } \\
\text { assets (at); numerator and denominator are constructed as the sum } \\
\text { of the current and two subsequent years; when missing reset to } \\
\text { annual measure, thereafter reset to } 0 \text {. }\end{array}$ \\
\hline RnDExp3 & $\begin{array}{l}\text { Research and development expenses (xrd) scaled by net sales } \\
\text { (sale); numerator and denominator are constructed as the sum of } \\
\text { the current and two subsequent years; when missing reset to } \\
\text { annual measure, thereafter reset to } 0 \text {. }\end{array}$ \\
\hline
\end{tabular}



net sales (sale); numerator and denominator are constructed as the sum of the current and two subsequent years; when missing reset to annual measure, thereafter reset to 0 .

Size3 The natural $\log$ of total assets (at) for the respective and two subsequent periods; when missing reset to annual measure, thereafter reset to 0 .

*Continuous firm controls are winsorized at $\mathrm{p} 1$ and p99 and not mean centered. 


\section{Figures}

\section{Figure 1}

Literature on Tax Knowledge Diffusion

\begin{tabular}{|c|c|c|}
\hline Framework & Intermediary & Peer-to-Peer \\
\hline $\begin{array}{c}\text { Major } \\
\text { Channel }\end{array}$ & A Explicit Transfer & Spillover \\
\hline A & \multicolumn{2}{|c|}{$\begin{array}{ll}\text { - } & \text { Auditors (Frey (2018); Lim et al. (2018)) } \\
\text { - } & \text { Banks (Gallemore, Gipper, Maydew (2018)) } \\
\text { - } & \text { Board Ties (Brown (2011); Brown, Drake (2014)) } \\
\text { - } & \text { Human Capital Turnover (Barrios, Gallemore (2018)) }\end{array}$} \\
\hline A & \multicolumn{2}{|c|}{ - Supply Chains (Cen et al. (2017); Cen et al. (2018)) } \\
\hline B & - Strategic Alliances & \\
\hline
\end{tabular}

This figure categorizes prior research regarding tax knowledge diffusion. It aligns the framework (institutional setting) of the identified channels. 


\section{Figure 2}

\section{Identification Strategy}

No tax knowledge diffusion without a sophisticated tax planner as partner

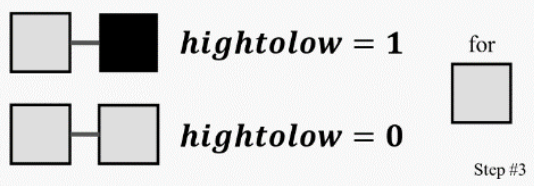

$t_{-2}$
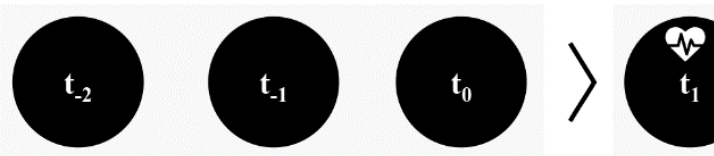

$\mathbf{t}_{1}$
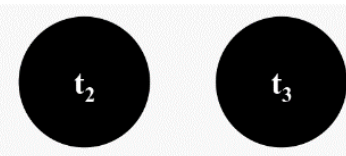

pre cash ETR3 $\left[t_{-2} ; t_{0}\right]$

$\operatorname{cash} \operatorname{ETR} 3\left[t_{1} ; t_{3}\right]$

- industry adjusted

- ranked according to quartiles

$\operatorname{cash} \operatorname{ETR} 3_{i, t=1}$

$=\beta_{0}+\beta_{1}$ hightolow $_{i, t=1}$

1

1 low-tax firm

high-tax firm $+\sum_{n} \beta_{n}$ partner controls $s_{i, t=1}^{n}$

$+\sum_{l} \beta_{l}$ network controls $l_{i, t=1}^{l}$

$+\sum_{k} \beta_{k}$ firm controls $s_{i, t=1}^{k}$

$+\delta_{\text {ind }}+\tau_{t}+\varepsilon_{i, t}$

This figure summarizes our identification strategy. For simplification purposes, we show the strategic alliances of two participants in the upper right corner. The heartbeat pictogram at $t_{1}$ indicates the year of initiation of a strategic alliance. We also show a specification of equation (3), where Tax Knowledge is measured as cash ETR3. 


\section{Figure 3}

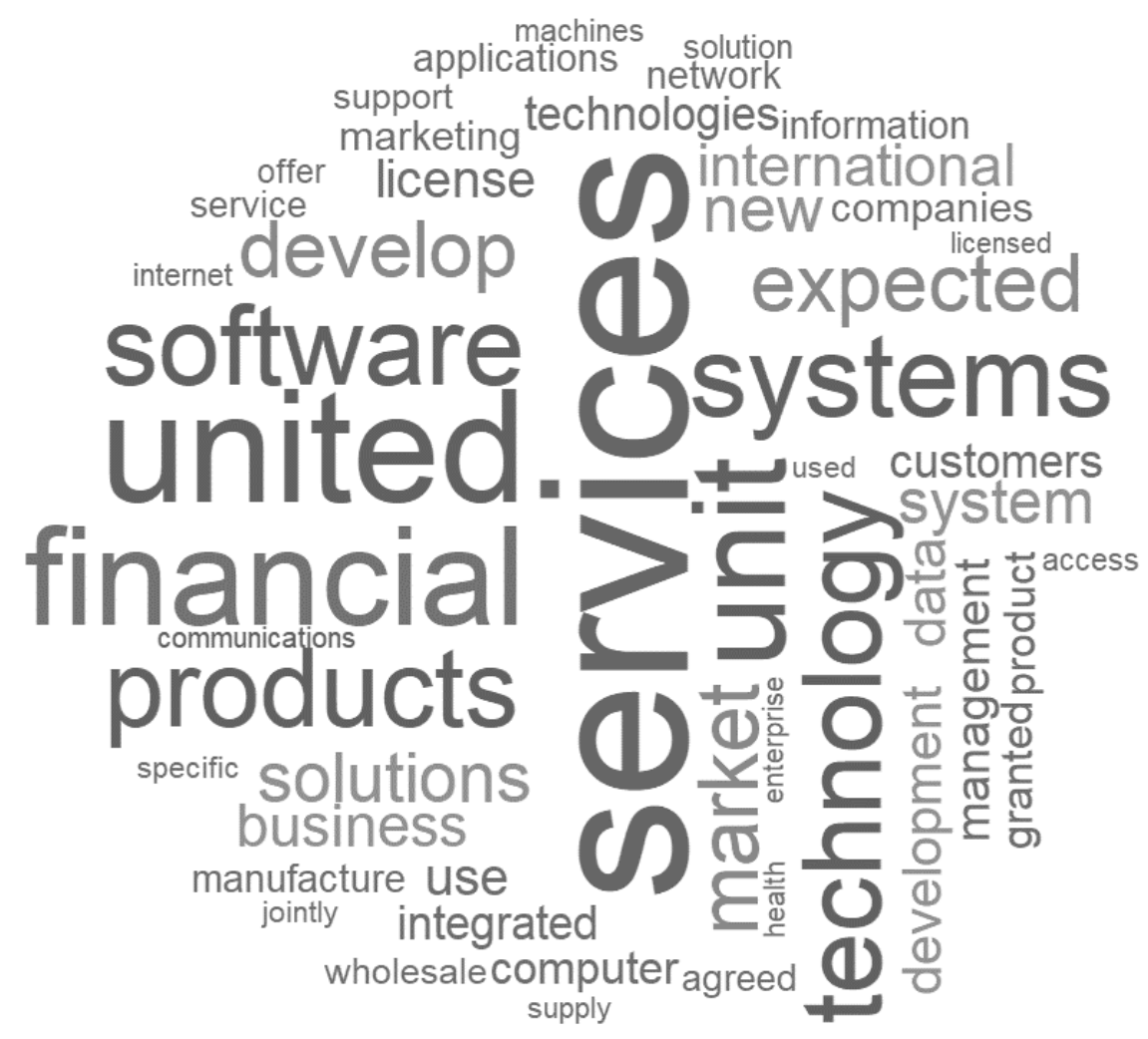

The word cloud depicted in Figure 3 shows the 50 most common words used in SDC's deal description of hightolow networks. By systematically searching through the deal descriptions, we identify wholesale, licensing, marketing and manufacturing activities as well as research and development, providing services and engaging in a supply chain as major business purposes of the networks in our sample. 


\section{Figure 4}

Panel A
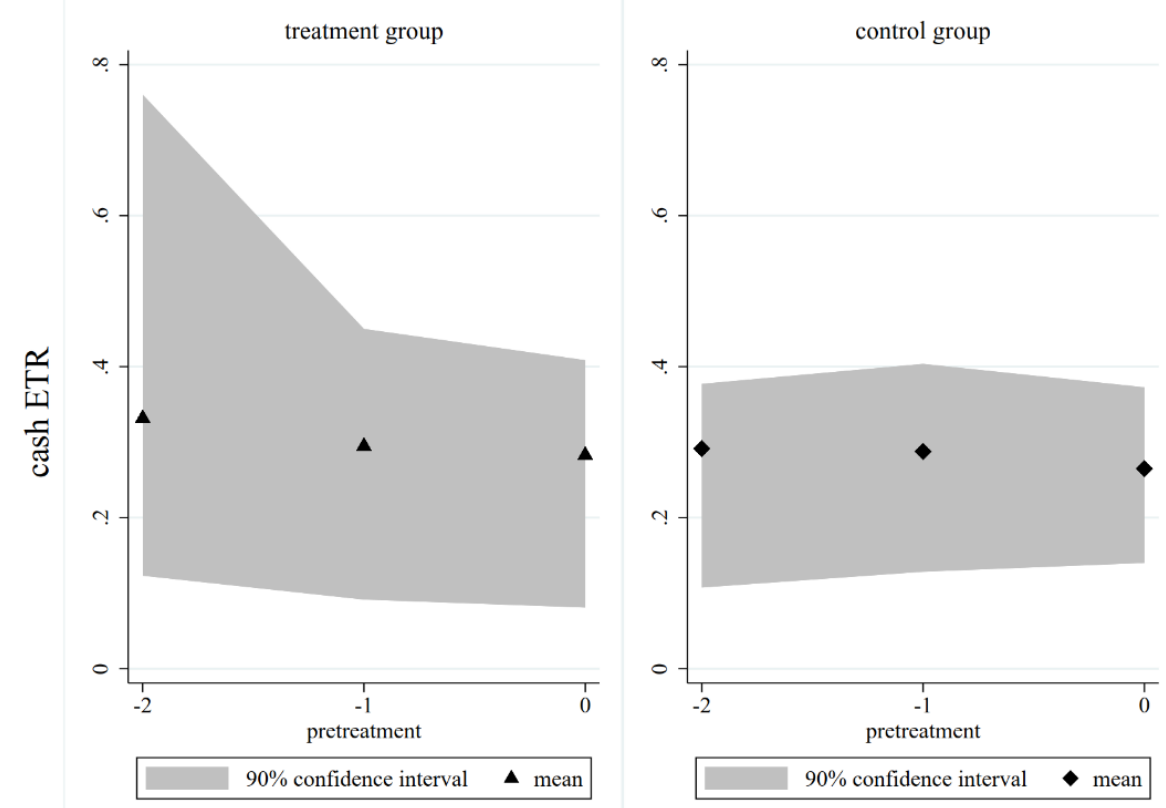

\section{Panel B}

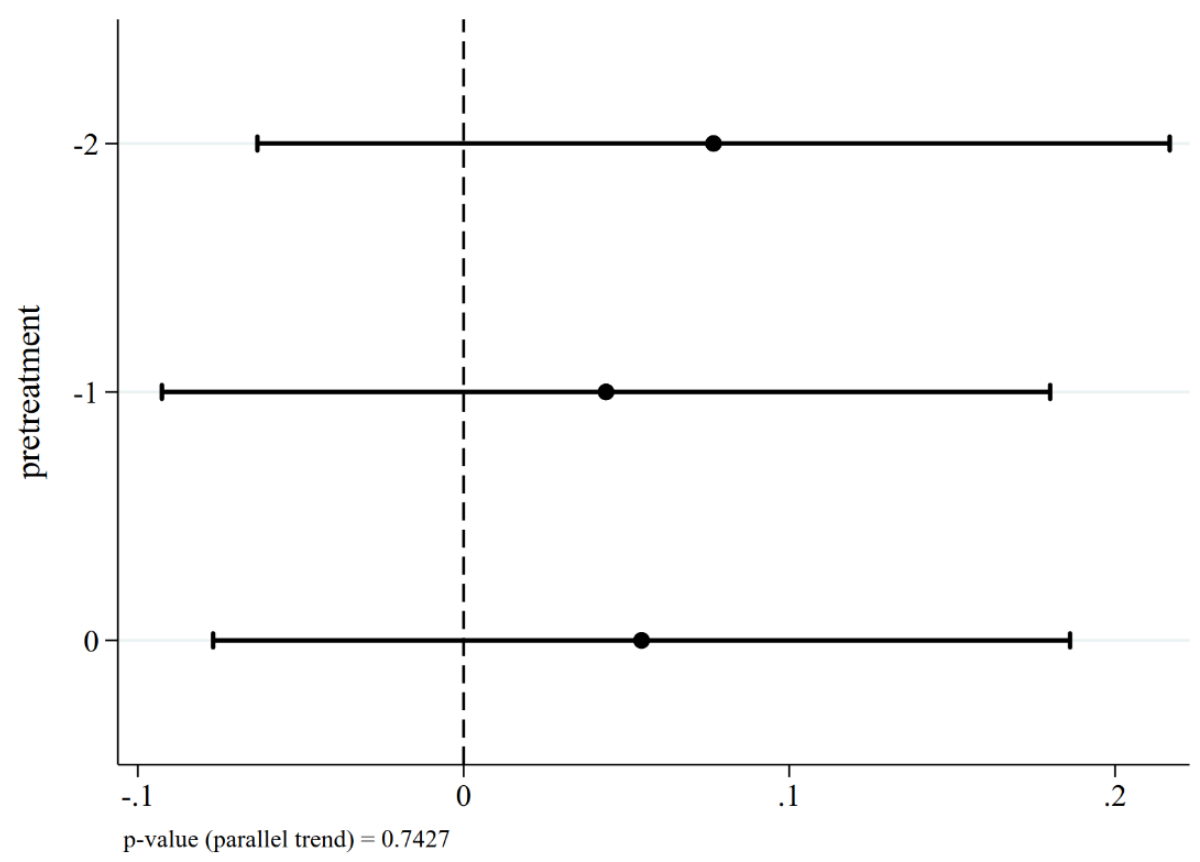

Panel A of this figure provides visual evidence that the trend of cash ETR is similar for treatment and control firms prior to the treatment. In Panel B, we apply the approach by Patel and Seegert (2015) to provide statistical evidence for the parallel trend assumption. The panel reports the coefficient and 95\% confidence interval of the interaction of the treatment indicator and time fixed effects for pretreatment years from the specification cash ETR $_{i, t}=\beta_{0}+\beta_{1} *$ treated $_{i}+\tau_{t}+\tau_{t} *$ treated $_{i}+\varepsilon_{i, t}$. We test that the coefficients on $\tau_{t} *$ treate $_{i}$ are jointly zero in the pretreatment period and fail to reject the null hypothesis. This supports the parallel trend assumption. The p-value for the parallel trend test is reported at the bottom of Panel B. 
Figure 5

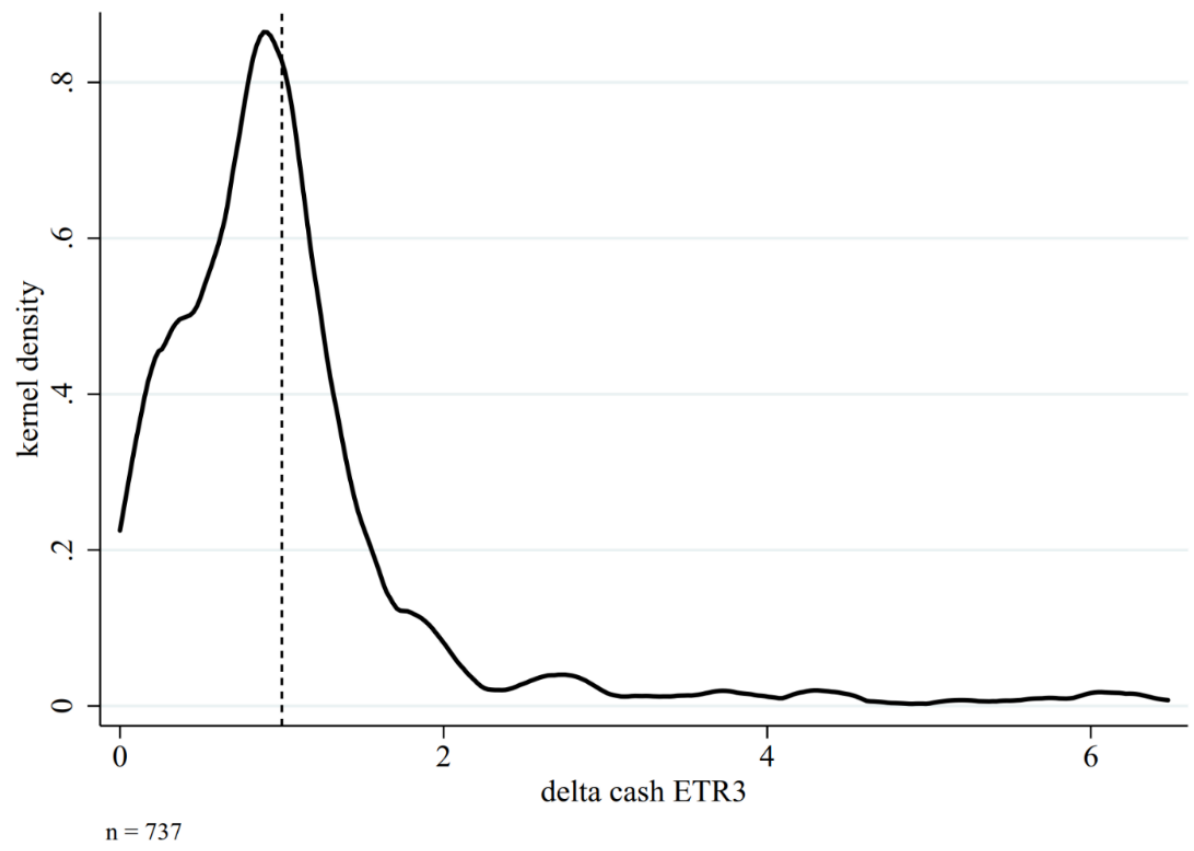

This figure depicts a kernel density plot of the distribution of delta cash ETR3 for high-tax firms. The dotted line at $\mathrm{x}=1$ indicates the threshold between a decrease and an increase in cash ETR 3 relative to pre cash ETR3. The Appendix contains detailed definitions of all variables. 
Figure 6

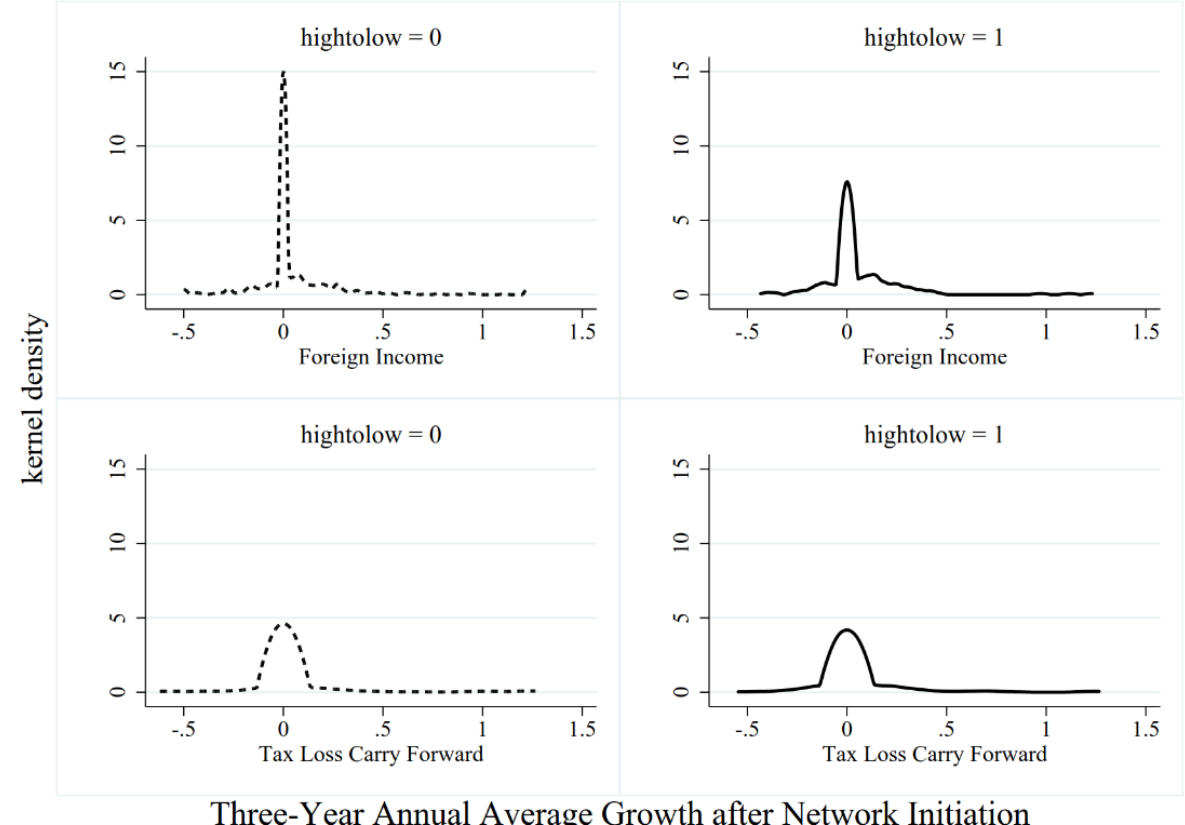

This figure depicts the kernel density distribution of the three-year annual average growth in foreign pretax income (pifo) and tax loss carry forward (tlcf) for high-tax firms in high-tax and low-tax networks (hightolow $=1$ vs. 0 ). 


\section{Tables}

\section{Table 1 Sample Selection \& Identification Strategy}

\section{Panel A Compustat \& SDC Platinum Data}

\begin{tabular}{|c|c|c|c|c|}
\hline & $\begin{array}{c}\text { network-firm- } \\
\text { observations }\end{array}$ & networks & firms & firm-years \\
\hline I. requirement to identify all contracting parties in network & 4159 & 2064 & 1603 & 19447 \\
\hline
\end{tabular}

\section{Panel B Identification Strategy: Missing Information}

all network-firm-observations in sample

network-firm-observations

missing pre cash ETR3 [t-2; t0]

./. missing cash ETR3 [t $1 ; \mathrm{t} 3]$

./. requirement to identify pre cash ETR3 and cash ETR3 of all participants in network

1301

\section{Panel C Identification Strategy: Classification of network-firm-observations}

\begin{tabular}{|c|c|c|c|}
\hline & low-tax partner & high-tax partner & $\sum$ \\
\hline low-tax firm [including multiple new networks of a firm in one year] & $58[78]$ & $159[225]$ & $217[303]$ \\
\hline high-tax firm [including multiple new networks of a firm in one year] & $197[226]$ & $540[772]$ & $737[998]$ \\
\hline & $255[304]$ & $699[997]$ & 954 [1301] \\
\hline
\end{tabular}

All variables are defined in detail in the Appendix. Data items from Compustat and SDC Platinum are in parentheses. 
Table 2 Information on Networks and Firms

Panel A pre cash ETR3 by pre taxrank

\begin{tabular}{lccccccccc}
\hline & $\mathrm{N}$ & $\mathrm{mean}$ & $\mathrm{min}$ & $\mathrm{p} 5$ & $\mathrm{p} 25$ & $\mathrm{p} 50$ & $\mathrm{p} 75$ & $\mathrm{p} 95$ & $\mathrm{max}$ \\
\hline pre taxrank =1 & 2872 & 0.0708 & 0.0000 & 0.0000 & 0.0228 & 0.0699 & 0.1136 & 0.1515 & 0.2213 \\
pre taxrank = 2 & 2872 & 0.2104 & 0.1055 & 0.1549 & 0.1836 & 0.2107 & 0.2367 & 0.2643 & 0.3255 \\
pre taxrank = 3 & 2872 & 0.3062 & 0.2161 & 0.2577 & 0.2801 & 0.3047 & 0.3316 & 0.3602 & 0.4197 \\
pre taxrank = 4 & 2872 & 0.6391 & 0.3094 & 0.3559 & 0.3973 & 0.4979 & 1.0000 & 1.0000 & 1.0000 \\
pre cash ETR3 & 11488 & 0.3066 & 0.0000 & 0.0141 & 0.1527 & 0.2599 & 0.3574 & 1.0000 & 1.0000 \\
\hline
\end{tabular}

Panel B Descriptive Statistics

\begin{tabular}{lccccccccc}
\hline & \multicolumn{1}{c}{ low-tax firm in network } & \multicolumn{3}{c}{ high-tax firm in low-tax } \\
& & \multicolumn{3}{c}{ network (hightolow = 1) } & \multicolumn{3}{c}{ high-tax firm in high-tax } \\
& $\mathrm{N}$ & mean & $\mathrm{p} 50$ & $\mathrm{~N}$ & mean & $\mathrm{p} 50$ & $\mathrm{~N}$ & mean & p50 \\
\hline cash ETR & 294 & 0.1396 & 0.1166 & 193 & 0.2708 & 0.2533 & 520 & 0.2918 & 0.2659 \\
cash ETR3 & 303 & 0.2017 & 0.1544 & 197 & 0.2755 & 0.2516 & 540 & 0.3282 & 0.2715 \\
cash ETR5 & 231 & 0.1836 & 0.1618 & 162 & 0.2366 & 0.2313 & 434 & 0.2697 & 0.2586 \\
EBITDA3 & 303 & 0.1387 & 0.1291 & 197 & 0.1527 & 0.1455 & 540 & 0.1582 & 0.1503 \\
RnDExp3 & 303 & 0.1031 & 0.0959 & 197 & 0.0737 & 0.0489 & 540 & 0.0614 & 0.0296 \\
AdExp3 & 303 & 0.0129 & 0.0000 & 197 & 0.0147 & 0.0000 & 540 & 0.0138 & 0.0000 \\
SGA3 & 303 & 0.3471 & 0.3363 & 197 & 0.2702 & 0.2720 & 540 & 0.2599 & 0.2432 \\
CapEx3 & 303 & 0.2082 & 0.1488 & 197 & 0.1536 & 0.1131 & 540 & 0.1598 & 0.1258 \\
ChangeSale3 & 303 & 0.0693 & 0.0524 & 197 & 0.0484 & 0.0337 & 540 & 0.0605 & 0.0393 \\
Leverage3 & 303 & 0.1681 & 0.1123 & 197 & 0.1815 & 0.1849 & 540 & 0.1942 & 0.1879 \\
Cash3 & 303 & 0.2647 & 0.2180 & 197 & 0.1818 & 0.1254 & 540 & 0.1657 & 0.1040 \\
MNE3 & 303 & 0.6931 & 1.0000 & 197 & 0.6041 & 1.0000 & 540 & 0.5444 & 1.0000 \\
NOL3 & 303 & 0.3432 & 0.0000 & 197 & 0.3503 & 0.0000 & 540 & 0.2722 & 0.0000 \\
Intangibles3 & 303 & 0.1556 & 0.0854 & 197 & 0.1844 & 0.1363 & 540 & 0.1585 & 0.0877 \\
PPE3 & 303 & 0.3067 & 0.2204 & 197 & 0.4116 & 0.3313 & 540 & 0.4341 & 0.3286 \\
Size3 & 303 & 9.1756 & 9.1257 & 197 & 9.6259 & 9.5942 & 540 & 9.1201 & 9.2695 \\
\hline
\end{tabular}


Table 2 Information on Networks and Firms (continued)

\section{Panel C Industry Affiliation of Networks and Firms (two-digit SIC-code)}

\begin{tabular}{|c|c|c|c|c|c|c|c|c|c|c|c|c|c|c|c|}
\hline & & \multirow[b]{2}{*}{ \# } & \multicolumn{12}{|c|}{ industry of networks } & \multirow[t]{2}{*}{$\Sigma$} \\
\hline & & & $\mathrm{I}$ & II & III & IV & $\mathrm{V}$ & VI & VII & VIII & IX & $\mathrm{X}$ & $\mathrm{XI}$ & XII & \\
\hline \multirow{9}{*}{ 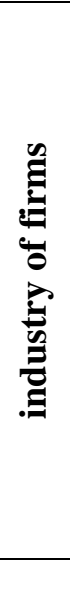 } & Mining (10-14) & II & 0 & 6 & 0 & 1 & 2 & 0 & 2 & 0 & 0 & 0 & 1 & 0 & 12 \\
\hline & Manufacturing: Chemical \& Allied Products (28) & IV & 0 & 0 & 0 & 26 & 15 & 0 & 23 & 0 & 20 & 8 & 35 & 0 & 127 \\
\hline & Manufacturing (20-39, except 28) & $\mathrm{V}$ & 0 & 4 & 2 & 11 & 167 & 17 & 41 & 4 & 39 & 131 & 48 & 7 & 471 \\
\hline & Transportation \& Public Utilities (40-49) & VI & 0 & 3 & 2 & 0 & 7 & 32 & 4 & 0 & 1 & 30 & 10 & 0 & 89 \\
\hline & Wholesale Trade (50-51) & VII & 0 & 1 & 0 & 0 & 3 & 2 & 19 & 1 & 3 & 8 & 4 & 0 & 41 \\
\hline & Services: Business Services (73) & $X$ & 0 & 0 & 0 & 1 & 31 & 10 & 21 & 3 & 22 & 273 & 22 & 3 & 386 \\
\hline & Services (70-89, except 73) & XI & 0 & 0 & 0 & 0 & 0 & 3 & 2 & 0 & 4 & 8 & 16 & 0 & 33 \\
\hline & Nonclassifiable Establishments (99) & XII & 0 & 0 & 0 & 3 & 8 & 6 & 1 & 0 & 4 & 15 & 8 & 0 & 45 \\
\hline & & & 0 & 14 & 4 & 44 & 238 & 78 & 124 & 10 & 122 & 500 & 153 & 14 & 1301 \\
\hline
\end{tabular}

All variables are defined in detail in the Appendix. 
Table 3 Descriptive Analysis

Panel A Comparison of cash ETR3 change between and within groups

high-tax firm in low-tax

network (hightolow $=1$ )

high-tax firm in high-tax

network (hightolow $=0$ )

\begin{tabular}{|c|c|c|c|c|c|c|c|}
\hline & & \multicolumn{2}{|c|}{ netwo } & \multicolumn{2}{|r|}{$010 \mathrm{~W}=$} & difference & \\
\hline Within-group change (hightolow $=1$ ) & I to II & & & & & $-0.1141 * * *$ & $(0.0000)$ \\
\hline Difference in within-group change & & & & & & $-0.0488 *$ & -1.6994 \\
\hline
\end{tabular}

Panel B Comparison of cash ETR3-development for intensified networking

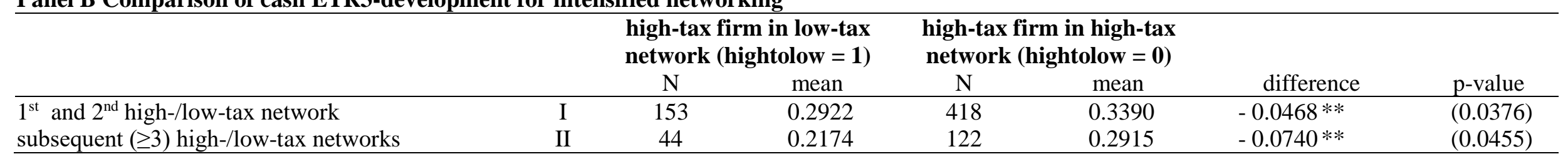

All variables are defined in detail in the Appendix. 
Table 4 Main Analysis

Panel A Regression Analysis

\begin{tabular}{|c|c|c|c|c|c|c|c|c|}
\hline Dependent variable & \multicolumn{2}{|c|}{ cash ETR3 } & \multicolumn{2}{|c|}{ delta cash ETR3 } & \multicolumn{2}{|c|}{ cash ETR5 } & \multicolumn{2}{|c|}{ delta cash ETR5 } \\
\hline hightolow & $-0.0480 * *$ & $(0.0103)$ & $-0.2062 * * *$ & $(0.0061)$ & $-0.0376 * * *$ & $(0.0087)$ & $-0.1229 * *$ & $(0.0191)$ \\
\hline Proximity & -0.0877 & $(0.1171)$ & -0.2488 & $(0.2795)$ & 0.0269 & $(0.4762)$ & 0.1089 & $(0.4028)$ \\
\hline SameAuditor & -0.0107 & $(0.6173)$ & -0.0427 & $(0.6201)$ & 0.0107 & $(0.5414)$ & 0.0309 & $(0.6342)$ \\
\hline Network controls & \multicolumn{2}{|c|}{ Yes } & \multicolumn{2}{|c|}{ Yes } & \multicolumn{2}{|c|}{ Yes } & \multicolumn{2}{|c|}{ Yes } \\
\hline Firm controls & \multicolumn{2}{|c|}{ Yes } & \multicolumn{2}{|c|}{ Yes } & \multicolumn{2}{|c|}{ Yes } & \multicolumn{2}{|c|}{ Yes } \\
\hline Observations & \multicolumn{2}{|c|}{ Firm } & \multicolumn{2}{|c|}{$\begin{array}{c}\text { Firm } \\
735\end{array}$} & 59 & & 59 & \\
\hline Adjusted R2 & \multicolumn{2}{|c|}{0.1233} & \multicolumn{2}{|c|}{0.1047} & \multicolumn{2}{|c|}{0.0577} & \multicolumn{2}{|c|}{0.1228} \\
\hline
\end{tabular}

Superscripts $* * *, * *$ and $*$ indicate significance at the $1 \%, 5 \%$ and $10 \%$ levels, respectively, for two-tailed tests. The results for equation (3) are presented in Panel A. Our main variable of interest is hightolow, which is an indicator variable set equal to 1 for observations of high-tax firms cooperating with low-tax firms and set equal to 0 for high-tax firms cooperating with high-tax firms. The number of observations is decreased from 737 to 735 (596 to 594 ) by two singleton observations in the fixed effects. All variables are defined in detail in the Appendix. 
Table 4 Main Analysis (continued)

Panel B Matched Panel: Difference-in-Differences

\begin{tabular}{|c|c|c|c|c|c|c|}
\hline \multirow[t]{2}{*}{ Dependent variable } & \multicolumn{2}{|c|}{ cash ETR } & \multicolumn{2}{|c|}{ cash ETR } & \multicolumn{2}{|c|}{ cash ETR } \\
\hline & coefficient & p-value & coefficient & p-value & coefficient & p-value \\
\hline treated & 0.0221 & $(0.3097)$ & 0.0140 & $(0.5047)$ & 0.0137 & $(0.5268)$ \\
\hline post & $0.0364 * *$ & $(0.0372)$ & $0.0374 * *$ & $(0.0291)$ & $0.0350 *$ & $(0.0536)$ \\
\hline treated*post & - $0.0695 * *$ & (0.0159) & - $0.0710 * *$ & $(0.0132)$ & $-0.0699 * *$ & (0.0131) \\
\hline Firm controls & $\mathrm{N}$ & & $\mathrm{N}$ & & Yes (annua & heasures) \\
\hline Fixed effects & $\mathrm{N}$ & & Indu & & Indu & \\
\hline SE cluster & Fir & & $\mathrm{Fi}$ & & $\mathrm{Fi}$ & \\
\hline Observations & 60 & & 60 & & 6( & \\
\hline Adjusted R2 & 0.0 & & 0.0 & & 0.0 & \\
\hline
\end{tabular}

Superscripts $* * *, * *$ and $*$ indicate significance at the $1 \%, 5 \%$ and $10 \%$ levels, respectively, for twotailed tests. Panel B depicts the results for equation (4). We compose our sample by creating an embargo period of eight years (from -3 to +5 years) around an hightolow observation during which no further hightolow observations may occur. We match control observations (hightolow $=0$ ) according to year and industry to each treatment occurrence (hightolow $=1$ ). All variables are defined in detail in the Appendix. 
Table 4 Main Analysis (continued)

\section{Panel C Adjustment Speed}

Dependent variable cash ETR

(\#) of specification coefficient $\quad$-value

(1) treated*post [t1] $\quad-0.0555$

(2) treated*post $[\mathrm{t} 1 ; \mathrm{t} 2] \quad-0.0988 * * \quad(0.0154)$

(3) treated*post $[\mathrm{t} 1 ; \mathrm{t} 3] \quad-0.0697 * * \quad(0.0423)$

(4) treated*post $[\mathrm{t} 1 ; \mathrm{t} 4] \quad-0.0765 * * \quad(0.0118)$

(5) treated*post $[\mathrm{t} 1 ; \mathrm{t} 5] \quad-0.0699 * * \quad(0.0131)$

\begin{tabular}{lc}
\hline Controls & Firm (annual measures) \& treated \& post \\
Fixed effects & Industry \\
SE cluster & Firm \\
Observations & $331 ; 405 ; 479 ; 545 ; 609$ \\
Adjusted R2 & $0.0403 ; 0.0505 ; 0.0359 ; 0.0420 ; 0.0431$ \\
\hline
\end{tabular}

Superscripts $* * *, * *$ and $*$ indicate significance at the $1 \%, 5 \%$ and $10 \%$ levels, respectively, for twotailed tests. Panel $\mathrm{C}$ depicts the results for five specifications of equation (4). The posttreatment period is extended by one year for each specification (from post $=1$ for $\left[t_{1}\right]$ to post $=1$ for $\left[t_{1} ; t_{5}\right]$ ). post remains 0 for $t_{-2}$ to $t_{0}$ throughout all specifications. The coefficient estimates for treatment $*$ post present the cumulative adjustment (i.e. adjustment speed) in a high-tax firm's tax planning behavior with progressing time when cooperating with low-tax firms. 
Table 5 Additional Analyses

Panel A Headquarters

\begin{tabular}{lcccc}
\hline Dependent variable & \multicolumn{2}{c}{ cash ETR3 } & \multicolumn{2}{c}{ delta cash ETR3 } \\
& coefficient & p-value & coefficient & p-value \\
\hline hightolow & $-0.0579 * * *$ & $(0.0033)$ & $-0.1912 * *$ & $(0.0107)$ \\
SameBEARegion & -0.0316 & $(0.1938)$ & -0.0474 & $(0.6590)$ \\
hightolow*SameBEARegion & $\mathbf{0 . 0 5 2 4}$ & $\mathbf{( 0 . 2 3 8 6 )}$ & $\mathbf{- 0 . 0 4 8 6}$ & $\mathbf{( 0 . 7 7 7 2 )}$ \\
\hline Controls & \multicolumn{2}{c}{ Network \& Firm } & \multicolumn{2}{c}{ Network \& Firm } \\
Fixed effects & Industry \& Year & \multicolumn{2}{c}{ Industry \& Year } \\
SE cluster & \multicolumn{2}{c}{ Firm } & \multicolumn{2}{c}{ Firm } \\
Observations & \multicolumn{2}{c}{735} & \multicolumn{2}{c}{735} \\
Adjusted R2 & \multicolumn{2}{c}{0.1233} & \multicolumn{2}{c}{0.1040} \\
\hline
\end{tabular}

Panel B Industry

\begin{tabular}{lcccc}
\hline Dependent variable & \multicolumn{2}{c}{ cash ETR3 } & \multicolumn{2}{c}{ delta cash ETR3 } \\
& coefficient & p-value & coefficient & p-value \\
\hline hightolow & $-0.0678 * * *$ & $(0.0078)$ & $-0.2505 * *$ & $(0.0197)$ \\
SameInd & $-0.0403 *$ & $(0.0530)$ & $-0.1567 *$ & $(0.0735)$ \\
& & & & \\
hightolow*SameInd & $\mathbf{0 . 0 5 2 6}$ & $\mathbf{( 0 . 1 2 6 7 )}$ & $\mathbf{0 . 1 3 4 8}$ & $\mathbf{( 0 . 3 2 3 5 )}$ \\
\hline Controls & \multicolumn{2}{c}{ Network \& Firm } & \multicolumn{2}{c}{ Network \& Firm } \\
Fixed effects & \multicolumn{2}{c}{ Year } & \multicolumn{2}{c}{ Year } \\
SE cluster & \multicolumn{2}{c}{ Firm } & \multicolumn{2}{c}{ Firm } \\
Observations & \multicolumn{2}{c}{736} & \multicolumn{2}{c}{0.1079} \\
Adjusted R2 & \multicolumn{2}{c}{0.1215} & \multicolumn{2}{c}{0.1079} \\
\hline
\end{tabular}


Table 5 Additional Analyses (continued)

Panel C Auditor

\begin{tabular}{|c|c|c|c|c|}
\hline \multirow{2}{*}{ Dependent variable } & \multicolumn{2}{|c|}{ cash ETR3 } & \multicolumn{2}{|c|}{ delta cash ETR3 } \\
\hline & coefficient & $\mathrm{p}$-value & coefficient & $\mathrm{p}$-value \\
\hline hightolow & $-0.0428 * *$ & $(0.0367)$ & $-0.2152 * * *$ & $(0.0077)$ \\
\hline SameAuditor & -0.0042 & $(0.8833)$ & 0.0594 & $(0.5950)$ \\
\hline hightolow*SameAuditor & - $\mathbf{0 . 0 2 3 7}$ & $(0.5566)$ & 0.0642 & $(0.6976)$ \\
\hline Controls & \multicolumn{2}{|c|}{ Network \& Firm } & \multicolumn{2}{|c|}{ Network \& Firm } \\
\hline Fixed effects & \multicolumn{2}{|c|}{ Industry \& Year } & \multicolumn{2}{|c|}{ Industry \& Year } \\
\hline SE cluster & \multicolumn{2}{|c|}{ Firm } & \multicolumn{2}{|c|}{ Firm } \\
\hline Observations & \multicolumn{2}{|c|}{735} & \multicolumn{2}{|c|}{735} \\
\hline Adjusted R2 & \multicolumn{2}{|c|}{0.1213} & \multicolumn{2}{|c|}{0.1037} \\
\hline
\end{tabular}

Superscripts $* * *, * *$ and $*$ indicate significance at the $1 \%, 5 \%$ and $10 \%$ levels, respectively, for twotailed tests. In Panel A, we test for the impact of geographical distance between the headquarters of cooperating firms. Distance is measured by an indicator variable that is set equal to one if network participants are headquartered in the same region, as defined by the Bureau of Economic Analysis, at network initiation. Panel B follows the approach of Panel A for the industry affiliation of network participants. We interact hightolow with an indicator for changes to a shared audit firm within three years of the network initiation in Panel C. All variables are defined in detail in the Appendix. 
Table 6 Robustness Checks: Alternative Explanations

Panel A Survivorship Bias

\begin{tabular}{lcc}
\hline Dependent variable & \multicolumn{2}{c}{ cash ETR3 } \\
Specification & \multicolumn{2}{c}{ exclude nonsurvivors } \\
& coefficient & p-value \\
\hline hightolow & $\mathbf{- 0 . 0 2 7 9 *}$ & $(\mathbf{0 . 0 5 7 1})$ \\
Proximity & -0.0663 & $(0.1718)$ \\
SameAuditor & -0.0109 & $(0.5264)$ \\
\hline Network controls & \multicolumn{2}{c}{ No } \\
Firm controls & \multicolumn{2}{c}{ Yes } \\
Fixed effects & Industry \& Year \\
SE cluster & \multicolumn{2}{c}{ Firm } \\
Observations & \multicolumn{2}{c}{638} \\
Adjusted R2 & \multicolumn{2}{c}{0.0966} \\
\hline
\end{tabular}

Panel C Impact on low-tax firms

\begin{tabular}{lcc}
\hline $\begin{array}{l}\text { Dependent variable } \\
\text { Specification }\end{array}$ & \multicolumn{2}{c}{ cash ETR3 } \\
& $\begin{array}{c}\text { only low-tax firms } \\
\text { coefficient }\end{array}$ & p-value \\
\hline lowtohigh & $\mathbf{- 0 . 0 0 0 2}$ & $\mathbf{( 0 . 9 9 6 1 )}$ \\
Proximity & 0.2021 & $(0.1885)$ \\
SameAuditor & -0.0140 & $(0.5520)$ \\
\hline Network controls & \multicolumn{2}{c}{ No } \\
Firm controls & \multicolumn{2}{c}{ Yes } \\
Fixed effects & Industry \& Year \\
SE cluster & \multicolumn{2}{c}{ Firm } \\
Observations & \multicolumn{2}{c}{301} \\
Adjusted R2 & \multicolumn{2}{c}{0.0666} \\
\hline
\end{tabular}

Panel B Increases in cash ETR3

\begin{tabular}{|c|c|c|}
\hline \multirow[t]{2}{*}{$\begin{array}{l}\text { Dependent variable } \\
\text { Specification }\end{array}$} & \multicolumn{2}{|c|}{$\begin{array}{c}\text { delta cash ETR3 } \\
\text { only if } \\
\text { delta cash ETR } \leq 1\end{array}$} \\
\hline & coefficient & $\mathrm{p}$-value \\
\hline hightolow & $-0.0543 *$ & $(0.0950)$ \\
\hline Proximity & -0.0398 & $(0.7199)$ \\
\hline SameAuditor & -0.0216 & $(0.5289)$ \\
\hline Network controls & \multicolumn{2}{|c|}{ No } \\
\hline Firm controls & \multicolumn{2}{|c|}{ Yes } \\
\hline Fixed effects & \multicolumn{2}{|c|}{ Industry \& Year } \\
\hline SE cluster & \multicolumn{2}{|c|}{ Firm } \\
\hline Observations & \multicolumn{2}{|c|}{455} \\
\hline Adjusted R2 & \multicolumn{2}{|c|}{0.1603} \\
\hline
\end{tabular}

Panel D Effect on Profitability

\begin{tabular}{lcc}
\hline Dependent variable & \multicolumn{2}{c}{ ChangeEBITDA3 } \\
& coefficient & p-value \\
\hline hightolow & $\mathbf{- 0 . 0 0 6 9}$ & $\mathbf{( 0 . 6 5 6 9 )}$ \\
Proximity & 0.0287 & $(0.4767)$ \\
SameAuditor & -0.0194 & $(0.1936)$ \\
\hline Network controls & \multicolumn{2}{c}{ Yes } \\
Firm controls & Yes (no EBITDA3) \\
Fixed effects & \multicolumn{2}{c}{ Industry \& Year } \\
SE cluster & \multicolumn{2}{c}{ Firm } \\
Observations & \multicolumn{2}{c}{735} \\
Adjusted R2 & \multicolumn{2}{c}{0.3577} \\
\hline
\end{tabular}

Superscripts $* * *, * *$ and $*$ indicate significance at the $1 \%, 5 \%$ and $10 \%$ levels, respectively, for twotailed tests. In Panel A, nonsurvivors are excluded from the sample. A firm is deemed a nonsurvivor if the year of network initiation is the final or penultimate fiscal year of coverage of this firm in our panel. Panel B excludes increases in cash ETR3 $\left[t_{1} ; t_{3}\right]$ in comparison to pre cash ETR $\left[t_{-2} ; t_{0}\right]$. We change our focus from high-tax to low-tax firms in Panel $\mathrm{C}$ and construct an indicator variable lowtohigh, which is set equal to one for low-tax firms in networks with high-tax firms and equal to zero for low-tax firms in networks with other low-tax firms. We cannot include network controls because we have the relevant information for networks of high-tax firms. In Panel D, we control for the (three-year) average annual growth rate in EBITDA (ChangeEBITDA3) subsequent to network initiation. All variables are defined in detail in the Appendix. 
Table 7 Robustness Checks: Identification Strategy

\section{Panel A Low-tax- and high-tax firms}

\begin{tabular}{|c|c|c|}
\hline $\begin{array}{l}\text { Dependent variable } \\
\text { Specification }\end{array}$ & $\begin{array}{r}\text { cash ETR3 } \\
\text { low-tax- } \\
\text { high-tax }\end{array}$ & $\begin{array}{l}{[\mathbf{t} \mathbf{1} ; \mathbf{t} 3]} \\
\text { and } \\
\text { firms }\end{array}$ \\
\hline & coefficient & p-value \\
\hline Own industry-adjusted pre cash ETR3 [t-2; t0] & $0.1606 * * *$ & $(\mathbf{0 . 0 0 0 0 )}$ \\
\hline Partner industry-adjusted pre cash ETR3 [t-2; t0] & $\mathbf{0 . 0 3 0 0}$ & $(\mathbf{0 . 2 8 2 8})$ \\
\hline Proximity & -0.0579 & $(0.1812)$ \\
\hline SameAuditor & -0.0133 & $(0.3777)$ \\
\hline SameInd & $-0.0249 *$ & $(0.0600)$ \\
\hline Network controls & No & \\
\hline Firm controls & Yes & \\
\hline Fixed effects & No & \\
\hline SE cluster & Firn & \\
\hline Observations & 127 & \\
\hline Adjusted R2 & 0.14 & \\
\hline
\end{tabular}

\section{Panel B Only high-tax firms}

Dependent variable

cash ETR3 [t1; t3]

Specification

high-tax firms only

coefficient $\mathrm{p}$-value

Own industry-adjusted pre cash ETR3 [t-2; t0] $\quad 0.0616 \quad(0.1216)$

Partner industry-adjusted pre cash ETR3 $[\mathrm{t}-2 ; \mathrm{t} 0] \quad 0.0592 * \quad(\mathbf{0 . 0 9 3 6})$

Proximity $\quad-0.0760$

SameAuditor

\begin{tabular}{ll} 
SameInd & $-0.0337 *(0.0551)$ \\
\hline Network
\end{tabular}

Network controls Yes

Firm controls $\quad$ Yes

Fixed effects

SE cluster $\quad$ Firm

Observations $\quad 728$

Adjusted R2 0.1211

Superscripts ***,** and * indicate significance at the $1 \%, 5 \%$ and $10 \%$ levels, respectively, for two-tailed tests. We examine correlations of cash effective tax rates between network participants. Panel A contains low-tax and high-tax firms in network-firm-observations. Panel B is limited to only high-tax firms. Both panels are limited to networks of two participants. We cannot include network controls in Panel A because we collected information for networks of high-tax firms. All variables are defined in detail in the Appendix. 


\section{Online Appendix: Information on Networks and Firms}

Random Sample of Networks and their main Business Purpose

\begin{tabular}{|c|c|c|c|c|}
\hline date effective & high-tax firm name (conm) & partner firm name (conm) & hightolow & deal description [extract] \\
\hline 17-May-95 & NOVELL INC & MICROSOFT CORP & 1 & $\begin{array}{l}\text { jointly provide customer service and support expertise in order to meet the needs } \\
\text { of customers who use products from both companies }\end{array}$ \\
\hline 06-Jun-95 & 3COM CORP & DSP GROUP INC & 1 & license to use speech compression technology for product (faxmodem) \\
\hline 29-Jan-96 & MCI COMMUNICATIONS & MICROSOFT CORP & 0 & jointly develop and market web services \\
\hline 11-Jun-97 & SCHERING-PLOUGH & DENDRITE INTERNATIONAL INC & 0 & license to provide database software services \\
\hline 26-Sep-97 & LOCKHEED MARTIN CORP & CSP INC & 0 & develop a processor \\
\hline 02-Feb-98 & PHARMACIA \& UPJOHN INC & CHIRON CORP & 0 & research Hepatitis $C$ virus and sharing of worldwide marketing rights \\
\hline 11-Jun-98 & CARPENTER TECHNOLOGY CORP & ROHM AND HAAS CO & 0 & license for usage of injection molding technology \\
\hline 06-Jul-98 & ELECTRONIC DATA SYSTEMS CORP & ENGINEERING ANIMATION INC & 0 & $\begin{array}{l}\text { cross-license and joint marketing and integration of applications to create } \\
\text { interface between visproducts and data management software }\end{array}$ \\
\hline 01-Dec-98 & ACTION PERFORMANCE COS INC & $\begin{array}{l}\text { CHAMPSHIP AUTO RACING } \\
\text { TEAM }\end{array}$ & 1 & $\begin{array}{l}\text { manufacture products (cart series and Fedex championship logos) in the United } \\
\text { States }\end{array}$ \\
\hline 06-Jan-99 & APPLIED MATERIALS INC & PLASMA-THEMR INC & 0 & license to cross-integrate product (cluster tool) \\
\hline 19-May-99 & SPARTAN MOTORS INC & FEDERAL SIGNAL CORP & 0 & purchase agreement to improve cost lines and benefit operating units \\
\hline 23-Apr-01 & CLOROX CO/DE & OIL DRI CORP AMERICA & 0 & wholesale and supply of products (cat litter) \\
\hline 21-Aug-02 & PEOPLESOFT INC & MERCURY INTERACTIVE CORP & 1 & accelerate implementation and upgrades of applications for customers \\
\hline $12-$ Sep-03 & BAXTER INTERNATIONAL INC & $\begin{array}{l}\text { CURATIVE HEALTH SERVICES } \\
\text { INC }\end{array}$ & 1 & wholesale of products (drugs for the prevention and control of bleeding) \\
\hline 22-Dec-03 & JOHNSON \& JOHNSON & ANIKA THERAPEUTICS INC & 1 & wholesale of products (drugs) with partial prepayment from Johnson \& Johnson \\
\hline 22-Jan-07 & LOCKHEED MARTIN CORP & BOEING CO & 1 & marketing and promotional services (air transportation system and equipment) \\
\hline 22-May-07 & PACER INTERNATIONAL INC & TRAILER BRIDGE INC & 1 & $\begin{array}{l}\text { provide freight services (container hauling) between United States and Puerto } \\
\text { Rico }\end{array}$ \\
\hline 22-Sep-08 & JOHNSON \& JOHNSON & ANIKA THERAPEUTICS INC & 1 & $\begin{array}{l}\text { wholesale and distribution of products (drugs for the treatment of pain) in South } \\
\text { America, Central America, the Caribbean and Mexico }\end{array}$ \\
\hline 18-Mar-09 & HARRIS CORP & MCAFEE INC & 0 & $\begin{array}{l}\text { develop software (cyber mission management and security software) to provide } \\
\text { network operators with heightened levels of situational awareness }\end{array}$ \\
\hline $12-F e b-13$ & PFIZER INC & AGILENT TECHNOLOGIES INC & 1 & $\begin{array}{l}\text { develop and commercialize companion diagnostics and provide advisory } \\
\text { services }\end{array}$ \\
\hline
\end{tabular}

This table provides information regarding the main business purpose of networks (random draw), which are classified either hightolow $=1$ or hightolow $=0$. 